\title{
Importance of integrating nanotechnology with pharmacology and physiology for innovative drug delivery and therapy - an illustration with firsthand examples
}

\author{
Rui Xue ZHANG ${ }^{1,2}$, Jason $\mathrm{LI}^{1}$, Tian ZHANG ${ }^{1}$, Mohammad A AMINI ${ }^{1}$, Chunsheng HE ${ }^{1}$, Brian $\mathrm{LU}^{1}$, Taksim AHMED ${ }^{1}$, HoYin LIP ${ }^{1}$, \\ Andrew M RAUTH ${ }^{4}$, Xiao Yu WU ${ }^{1, *}$ \\ ${ }^{1}$ Advanced Pharmaceutics \& Drug Delivery Laboratory, Leslie Dan Faculty of Pharmacy, University of Toronto, Toronto, Ontario, Canada; \\ ${ }^{2}$ School of Life Sciences, Northwestern Polytechnical University, Xi'an, China; ${ }^{3}$ Departments of Medical Biophysics and Radiation \\ Oncology, University of Toronto, Princess Margaret Cancer Centre, Toronto, Ontario, Canada
}

\begin{abstract}
Nanotechnology has been applied extensively in drug delivery to improve the therapeutic outcomes of various diseases. Tremendous efforts have been focused on the development of novel nanoparticles and delineation of the physicochemical properties of nanoparticles in relation to their biological fate and functions. However, in the design and evaluation of these nanotechnology-based drug delivery systems, the pharmacology of delivered drugs and the (patho-)physiology of the host have received less attention. In this review, we discuss important pharmacological mechanisms, physiological characteristics, and pathological factors that have been integrated into the design of nanotechnology-enabled drug delivery systems and therapies. Firsthand examples are presented to illustrate the principles and advantages of such integrative design strategies for cancer treatment by exploiting 1) intracellular synergistic interactions of drug-drug and drug-nanomaterial combinations to overcome multidrug-resistant cancer, 2) the blood flow direction of the circulatory system to maximize drug delivery to the tumor neovasculature and cells overexpressing integrin receptors for lung metastases, 3) endogenous lipoproteins to decorate nanocarriers and transport them across the blood-brain barrier for brain metastases, and 4) distinct pathological factors in the tumor microenvironment to develop $\mathrm{pH}$ - and oxidative stress-responsive hybrid manganese dioxide nanoparticles for enhanced radiotherapy. Regarding the application in diabetes management, a nanotechnologyenabled closed-loop insulin delivery system was devised to provide dynamic insulin release at a physiologically relevant time scale and glucose levels. These examples, together with other research results, suggest that utilization of the interplay of pharmacology, (patho-) physiology and nanotechnology is a facile approach to develop innovative drug delivery systems and therapies with high efficiency and translational potential.
\end{abstract}

Keywords: nanotechnology; pharmacology; physiology; pathophysiology; drug delivery systems; drug synergism; blood-brain barrier; tumor metastasis; diabetes mellitus; anticancer therapy

Acta Pharmacologica Sinica (2018) 39: 825-844; doi: 10.1038/aps.2018.33; published online 26 Apr 2018

\section{Introduction}

The application of nanotechnology in drug delivery has gained increasing interest over the past few decades ${ }^{[1,2]}$. A myriad of nanoparticles (NPs) have been constructed using various polymers, lipids, inorganic materials or their combinations with the desired physicochemical properties and biological functions for the treatment of various diseases ${ }^{[1,3,4]}$, such

\footnotetext{
*To whom correspondence should be addressed.

E-mail xywu@phm.utoronto.ca

Received 2018-01-09 Accepted 2018-02-19
}

as cancer ${ }^{[5-7]}$, diabetes ${ }^{[8,9]}$, and central nervous system (CNS) disorders ${ }^{[10,11]}$. In general, NP formulations are capable of enhancing drug efficacy and reducing normal tissue toxicity in preclinical studies; however, their conversion to approved clinical uses has been limited ${ }^{[12,13]}$. In addition to financial, ethical and regulatory hurdles to drug development ${ }^{[13,14]}$, insufficient attention to the correlations between individual patient biology and NPs and between the pharmacology of delivered drugs and the NP design may also contribute to the low rate of translation from the bench to bedside $\mathrm{e}^{[13,15,16]}$.

The majority of studies in the field of nanomedicine have 
focused on the development of new NP systems and delineation of their physicochemical properties in relation to their biological fate and functions, particularly in cancer diagnosis and therapy ${ }^{[17,18]}$. Typically, NP physicochemical parameters such as particle size, shape, surface charge, surface ligand modification and chemistry are optimized to overcome one or more aspects of macroscopic (whole body) and microscopic biological barriers via the solid tumor enhanced permeability and retention (EPR) effect ${ }^{[19,20]}$ or active targeting by ligandreceptor interactions (Figure 1$)^{[3,17]}$. Compared to free drugs in solution form, drugs encapsulated in NPs exhibit different pharmacokinetics (eg, extended half-life time) and improved tumor targeting, leading to higher tumor accumulation of the nanocarriers ${ }^{[12,21,22]}$. However, to be biologically effective, the NPs must bring the drug concentration to the therapeutic level at the drug target sites (eg, nuclear DNA, mitochondria) (Figure 1, right panel). The local bioavailability of NP-delivered drugs largely depends on whether the NPs can gain entry to the cancer cells and release their cargo at the site of drug action at a therapeutically effective rate ${ }^{[3,23,24]}$. These characteristics of NPs, while critical for their therapeutic effect, have not received adequate attention in the conventional design of nanomedicine. For example, the clinically used liposomal for- mulation (ie, Doxil $\left.{ }^{\circledR}\right)$ is known to reduce the cardiotoxicity that is commonly associated with free doxorubicin (DOX) solution, but it does not efficiently enter cancer cells and release the loaded DOX intracellularly ${ }^{[2,26]}$. As a result, it does not demonstrate improved efficacy compared to free DOX in solution despite its increased half-life and tumor accumulation and reduced cardiotoxicity ${ }^{[27,28]}$. Therefore, in the application of nanotechnology to drug delivery, the design of nanocarriers must be placed in the context of the pharmacology of the delivered drugs, that is, to deliver the drugs to the right site at the right time and the right levels (3Rs).

The ultimate goal of the clinical use of drug delivery systems is to enhance drug efficacy while reducing unwanted normal tissue side effects. To achieve this goal, the $3 R s$ are essential and are applicable not only to injectable nanomedicine for cancer therapy but also to other nanotechnologybased devices or carriers that release an active pharmaceutical ingredient (API) in response to disease state-associated stimuli (eg, elevated glucose concentrations in diabetes mellitus or the tumor microenvironment (TME) in cancer) ${ }^{[9,24,29,30]}$. In spite of advances in nanotechnology, the in vivo performance of drug delivery systems often does not meet the medical need. One solution to this inadequacy is to thoroughly understand drug

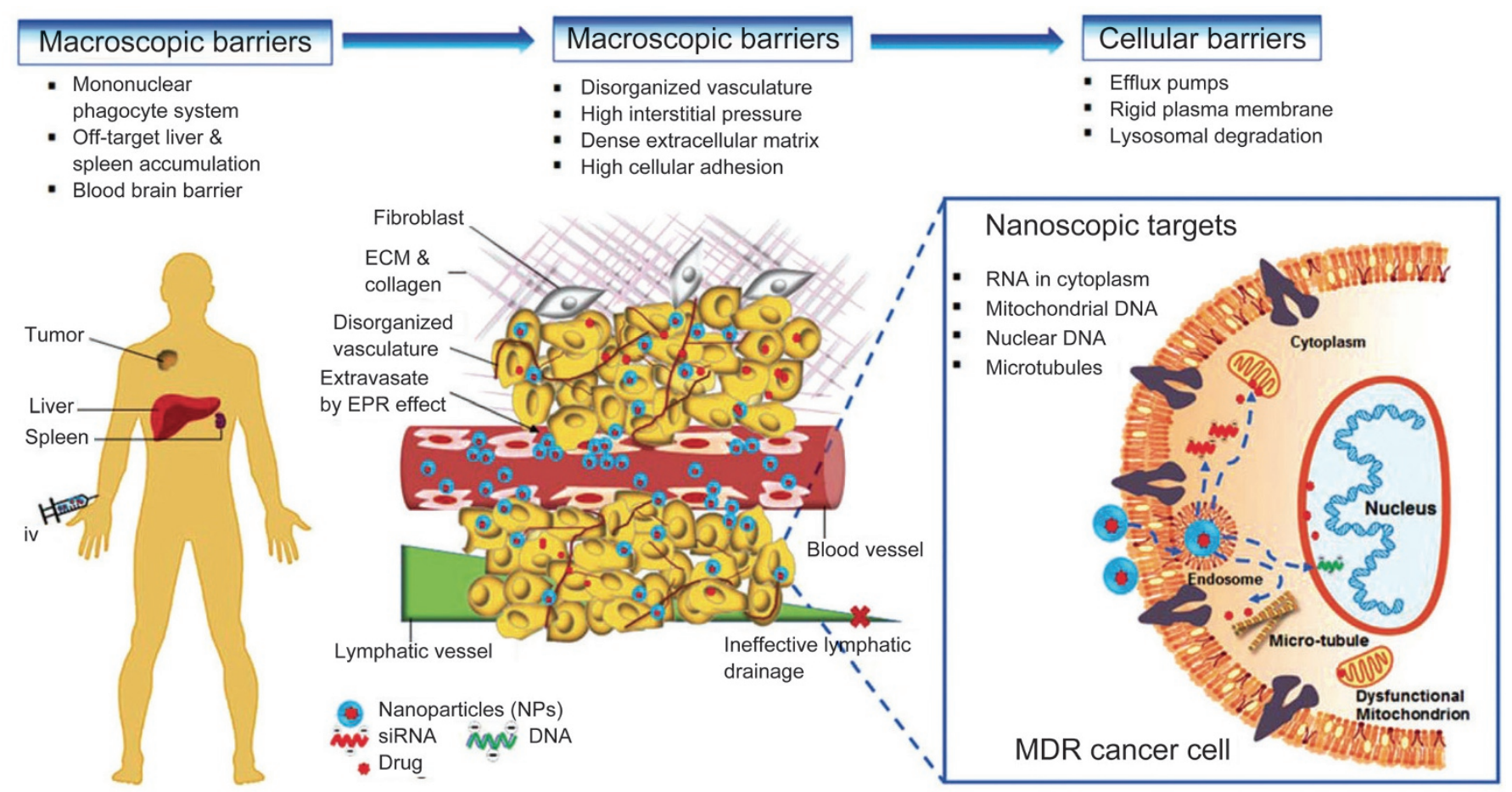

Figure 1. Illustration of multiple biological barriers to NPs and its delivered drugs before reaching nanoscopic targets of diseased cells. Left panel: at the macroscopic level (non-cellular), iv administered NPs are sequestered, accumulated and eventually eliminated by mononuclear phagocytic system (MPS) consisting mainly of the liver and spleen. In addition, the blood-brain barrier (BBB) is highly selective for many foreign substances, thus, preventing the entry of drug containing NPs into the brain. Middle panel: at the microscopic level (non-cellular), the complex tumor microenvironment (TME), eg, poor neo-vasculatures, dense extracellular matrix (ECM), limits the tumor permeation and retention of NPs, leading to low drug accumulation at the tumor necrotic region. Right panel: at the cellular level, the nucleus and mitochondrion are the primary organelles of genetic mutation responsible for complicated MDR phenotypes, such as overexpression of efflux transporters (eg, P-gp), membrane rigidity, lysosomal sequestration, apoptosis evasion, drug detoxification and altered drug target. All of the MDR mechanisms can occur simultaneously to confer drug resistance, leading to sub-optimal therapies. The figure is reproduced from Zhang et $a^{[3]}$ with permission. 
pharmacology, human physiology and disease pathology and integrate each aspect into the design and evaluation of drug delivery systems for specific diseases.

In this review, we address an important question in the field of nanotechnology-based drug delivery: how can we harness the interplay between biology and nanotechnology to develop clinically relevant drug delivery systems at low cost and a high success rate? Important pharmacological and physiological mechanisms and pathological features of diseases are described for exploitation in the design of nanotechnology-enabled drug delivery systems and therapies. Firsthand examples from our research of improving therapies of cancer and diabetes are presented to illustrate the principles and importance of integration of nanotechnology with pharmacology and (patho-)physiology. The rational design of various target- and disease-driven nanotechnology-based systems are explored by (1) elucidating the molecular mechanisms of synergistic drug combinations; (2) exploiting circulatory system physiology; (3) harnessing the brain transport pathway of naturally occurring lipoproteins; (4) tackling hypoxia in the TME; and (5) mimicking physiologically relevant insulin release. It is hoped that the insights gained from these research explorations on drug delivery systems can build a bridge between the fields of nanomaterials and biological systems and provide a new perspective for the design and development of clinically useful nanomedicines.

\section{Integration of nanotechnology with pharmacology for enhanced chemotherapy in multidrug-resistant cancer}

Multidrug resistance (MDR) in cancer is a common clinical problem. It involves complex cellular and non-cellular mechanisms (eg, the aberrant TME), which can collectively contribute to reduced drug concentrations, activities and efficacy at tumor sites and within cancer cells, leading to ineffective chemotherapy ${ }^{[31-33]}$. To overcome the multifactorial MDR mechanisms for improved chemotherapy, various approaches have been investigated, such as the development of new anticancer drugs that are poor substrates for efflux transporters (eg, P-glycoprotein (P-gp)), MDR modulators or chemo-sensitizers (eg, inhibitors of P-gp); downregulation of MDR-associated enzymes using RNA interference; synergistic drug combination with different mechanisms of drug actions and multifunctional NPs ${ }^{[6,34,35]}$. In our laboratory, solid polymer-lipid hybrid NPs (PLNs) have been designed to bypass efflux transporters and synergistic drug combinations or drug-nanomaterial combinations in NPs have been explored $^{[3,4,6,21,32,36-42]}$.

In the clinic, to counteract MDR in cancer, drug combination therapy is commonly used as the standard of care for a broad range of cancers in which single drug therapies are ineffective ${ }^{[43,44]}$. Often, drugs in combination are selected based on their different mechanisms of action, the lack of cross-drug resistance and the generation of synergistic (ie, more-thanadditive) effects ${ }^{[6,45]}$. Ideally, a rationally selected synergistic drug combination should provide new therapeutic possibilities via different mechanisms of drug action while simultane- ously minimizing normal tissue side effects due to the reduced dose of each drug. However, the clinical outcome of combination therapy is often confounded by severe adverse normal tissue effects with little improvement in efficacy ${ }^{[45]}$. In many cases, drug combinations show strong cytotoxicity in vitro; however, once administered intravenously (iv) into the body, the drug combination non-specifically distributes to normal organs before reaching the tumor due to the different pharmacokinetic profiles of each drug, resulting in increased adverse effects $^{[6]}$. In addition, even if the drugs arrive at the tumor site, the synergistic ratio of the drug combination may not be maintained.

Application of nanotechnology in drug delivery makes it possible to deliver synergistic drug combinations ratiometrically and spatial-temporally to the sites of drug action $^{[3,6,21,36-38,46-52]}$. With deepened understanding of the molecular mechanisms involved in specific drug combinations and the use of nanosized drug carriers, several nanoparticle formulations of synergistic drug combination have been moved to clinical trials ${ }^{[46-50,53]}$ or have gained approval by the United States (US) Food and Drug Administration (FDA) or other regulatory agencies ${ }^{[54,55]}$. In the following sections, the importance of intracellular drug-drug and drug-nanomaterial interactions in the rational design of synergistic combination nanomedicines is explained in more detail.

\section{a) Harnessing intracellular drug-drug interactions to design synergistic nanomedicine}

The initiative of combining two clinically used anticancer drugs, DOX and mitomycin C (MMC), stemmed from their differences in mechanism of action and activation under hypoxia. It is known that under the hypoxic conditions of the TME, the cytotoxicity of DOX is attenuated, as its activity partially relies on the presence of oxygen $\left(\mathrm{O}_{2}\right)$ to generate free radicals (ie, superoxide) that can cause DNA damage $^{[33,56]}$. In contrast, MMC can be activated under hypoxia through a sequential one electron reduction pathway that enhances its cytotoxicity and can generate free radicals under normoxia (ie, in the presence of oxygen $)^{[57,58]}$. In addition, DOX and MMC damage DNA by different mechanisms: DOX causes DNA double-strand breaks by poisoning topoisomerase $\mathrm{II}_{\alpha}\left(\mathrm{TII}_{\alpha}\right)$, an enzyme responsible for catalyzing the unwinding of DNA for transcription and replication ${ }^{[59,60]}$, whereas MMC induces DNA intra-strand and inter-strand crosslinks to disrupt cell maintenance and replication ${ }^{[61]}$. However, the clinical combination of DOX and MMC (DOXMMC) was halted owing to its severe cardiotoxicity to cancer patients ${ }^{[62,63]}$. We perceived that this off-target adverse effect could be reduced with optimal scheduling and dosing of the two drugs by rationally designing a drug nanocarrier system ${ }^{[64-68]}$.

With knowledge of the mechanistic actions of DOX and MMC individually in cancer cells, we first investigated whether combining DOX and MMC could generate synergistic cytotoxicity in multiple murine and human breast cancer cell lines. Detailed in vitro pharmacological studies on the 
DOX-MMC combination showed that the MMC bio-reductive metabolism, leading to the formation of activated MMC and formaldehyde, played an important role in the synergistic interaction between DOX and MMC (Figure 2A) ${ }^{[66]}$. The resultant formaldehyde depletion of glutathione (GSH), an important antioxidant that can decrease intracellular DOX concentration and reactive oxygen species (ROS)-associated cellular damage, causes the higher cytotoxicity of DOX. In addition, formaldehyde reacted with DOX to produce an active form of DOX, doxoform, that can crosslink DNA. The significantly increased DNA crosslinking adducts during the DOX-MMC treatment triggered the activation of the DNA repair enzyme system by DOX, which in turn promoted their collision with stalled $\mathrm{TII}_{\mathrm{a}}$, leading to enhanced DNA double-strand breaks in cancer cells and subsequent cell apoptosis ${ }^{[66]}$. This proposed interaction mechanism suggested a critical window for treatment exposure of the DOX-MMC combination to achieve anticancer synergism because cancer cells are able to recover from MMC-induced metabolic disruption (eg, reduced GSH) and DNA lesions within a short time interval $(<4 \mathrm{~h})^{[69]}$. The synergistic DOX-MMC combination could be used against cancer cells that have sufficient bio-reductive enzymes to activate MMC.

To determine whether co-delivery of the DOX-MMC combination by the same nanocarrier is important for their synergism, the schedule and sequence of drug administration were studied ${ }^{[67,68]}$. Screening the effects of various exposure schedules and doses of the DOX-MMC combination on the survival of breast cancer cells revealed that the synergism occurred only when MMC was administered either simultaneously with or after DOX exposure at an optimum DOX-toMMC molar ratio of 2:1 but not when MMC was given prior to DOX ${ }^{[67,68]}$. Based on these findings, a PLN formulation coloaded with DOX-MMC (DMPLN) was designed with a key capability of synchronizing co-delivery of locally bioavailable DOX-MMC combination at synergistic ratios to cancer cells (Figure 2B (i)\&(ii) $)^{[36,65]}$. As a result, DMPLN provided superior advantages over free DOX-MMC solution and liposomal DOX (DOXIL $\left.{ }^{\circledast}\right)$ with enhanced tumor cell apoptosis and minimum cardiotoxicity (Figure 2B (iii)\&(iv)), as well as prolonged host-survival in both human and murine MDR tumor models ${ }^{[25,37,38]}$.

\section{b) Exploiting intracellular drug-nanomaterial interactions to} design in situ bio-activated nanomedicine

In general, NPs can circumvent efflux pumps in MDR cancer cells via endocytosis pathways ${ }^{[32,41,70]}$. However, in some MDR cells, in addition to overexpressing drug efflux transporters (ie, P-gp), the rigid and thickened cellular membrane restricts the drug influx and NP uptake as a result of increased cholesterol and sphingolipid content in the cancer cell membrane compared to non-resistant ones ${ }^{[71-74]}$. Imbalance of cholesterol homeostasis is also associated with obesity and breast cancer ${ }^{[75-77]}$. To overcome such multifactorial MDR in cancer cells, we have rationally designed a sequential two- step targeting PLN system containing the ROS-generating anticancer drug MMC and the polyunsaturated fatty acid docosahexaenoic acid (DHA) ${ }^{[78]}$. DHA is capable of improving cell membrane fluidity due to the presence of six carbon-carbon double bonds within its chemical structure ${ }^{[79]}$. Thus, as a liquid lipid nanomaterial of the PLN, the DHA component, as the "first punch", softened the rigid membrane of MDR cancer cells, facilitating cellular entry of the NPs. Subsequently, in situ enzymatic bio-activation of MMC near or inside the mitochondria produced free radicals that initiated an intracellular chain reaction of lipid peroxidation of DHA and endogenous lipids (Figure $3 \mathrm{~A})^{[78,80]}$. The entire course of the intracellular anticancer synergistic interaction of MMC and DHA was accomplished by the nanocarrier PLN co-loaded with MMC-DHA at a fixed ratio (MMC-DHA-PLN). The nanotechnology-enabled system acted as a targeted "nanoreactor" that coordinated and maximized the synergistic reactions between MMC and DHA at intracellular targets (eg, mitochondria). Compared to the non-co-encapsulated free MMC-DHA combination, MMC-DHA-PLN ensured the proximate interactions between MMC and DHA at each subsequent delivery step from the reduction in membrane rigidity to the enhancement in mitochondrion-targeted toxicity (Figure 3B ${ }^{[78]}$. As anticipated, MMC-DHA-PLN had markedly enhanced anticancer cytotoxicity against MDR cells in vitro and inhibited tumor growth with no adverse effects detected in an orthotopic MDR breast tumor model ${ }^{[78]}$.

\section{Integration of nanotechnology with physiological transport for targeting cancer metastases in the lungs and brain}

Cancer metastasis from the primary tumor to distant organs, such as the lungs, liver and brain, is a devastating medical condition that contributes to the majority of cancer-related deaths ${ }^{[81,82]}$. To treat metastases, conventional chemotherapy and radiotherapy and newly emerging targeted therapy (eg, neutralizing antibody to growth factors) are the main treatment modalities ${ }^{[81,82]}$. Nonetheless, the current clinical treatments for tumor metastases are far from optimal due to their severe adverse effects and limited efficacy (eg, drug resis-

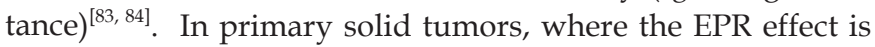
pronounced, NPs typically can minimize normal organ toxicity and enhance therapeutic efficacy via passive or active targeted drug delivery ${ }^{[19,85]}$. However, the EPR effect may not occur in metastatic tumors, especially when they are at an early stage and present as micron-sized lesions ${ }^{[86,87]}$. Moreover, owing to the highly selective biological barriers presented in Figure 1, including the predominant hepatic removal of foreign particles and the blood brain barrier (BBB), off-target accumulation of NPs in unintended organs occurs frequently ${ }^{[88]}$. Therefore, it is challenging to transport NPs to metastatic tumors by simple passive and/or active targeting approaches. In the following examples, we present strategies developed from our research work to mitigate these challenges by exploiting the natural systemic circulation and brain transport pathways. 
A

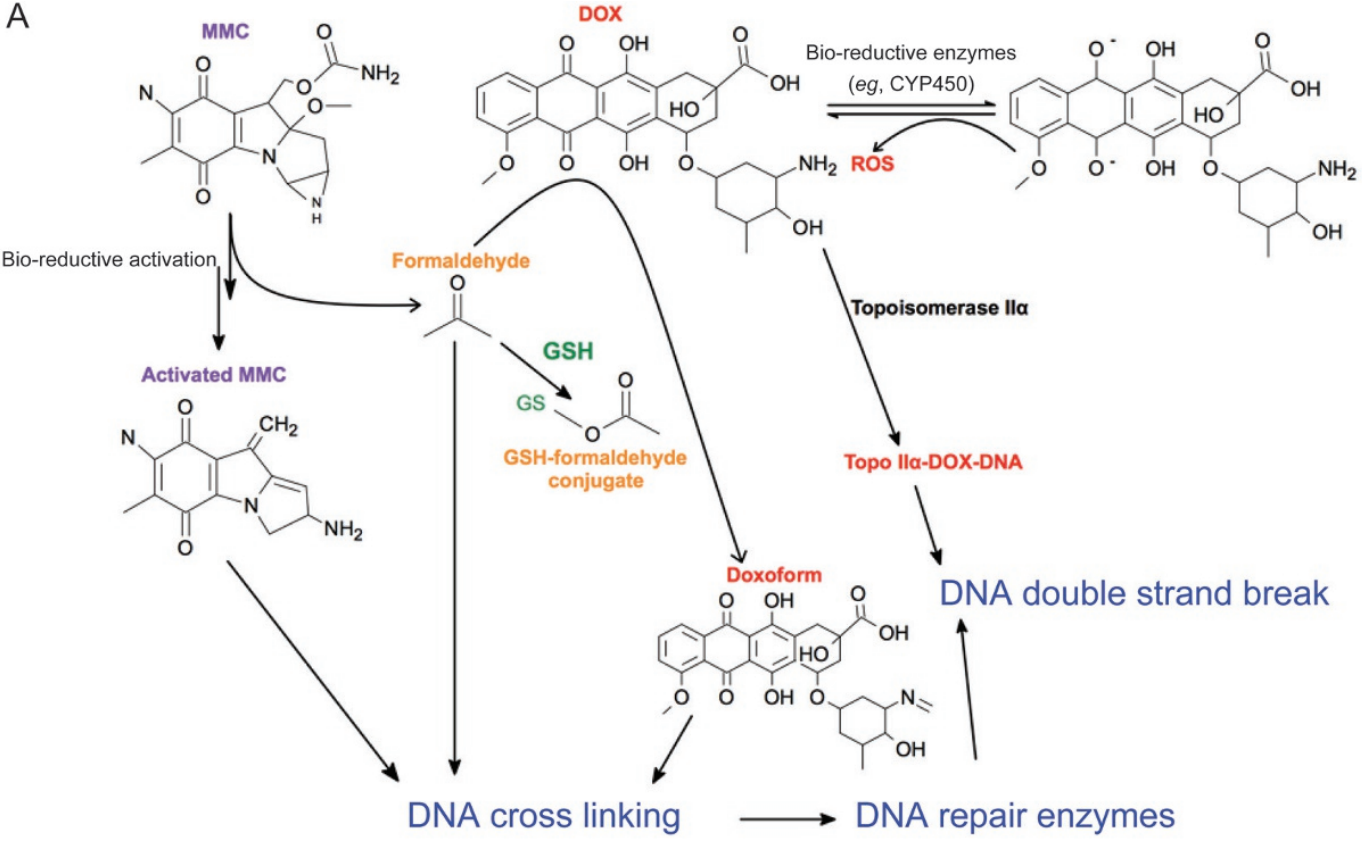

B

(i) Prolonged systemic circulation

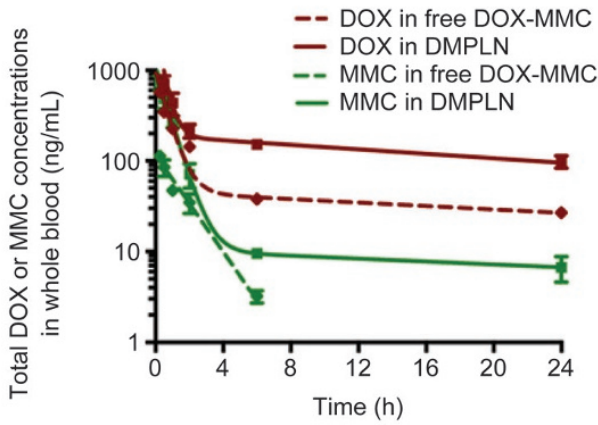

(iii) Enhanced tumor cell apoptosis

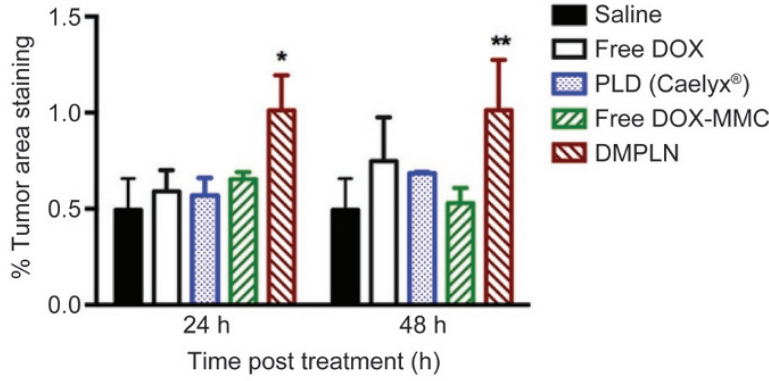

(ii) Ratio-metric tumor delivery

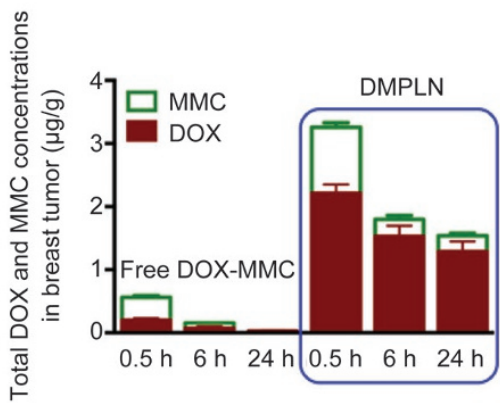

(iv) Reduced cardiotoxicity

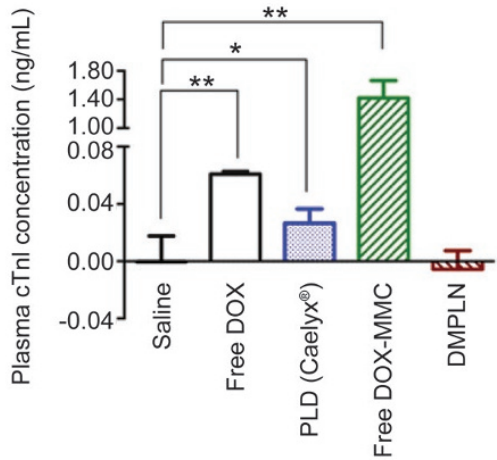

Figure 2. Biochemical interactions between anticancer drugs, DOX and MMC, and their ratio-metric co-delivery using DMPLN. (A) Synergistic interaction of DOX-MMC combination. The bio-reductive metabolism of anticancer pro-drug MMC plays a key role in enhancing DNA crosslinking, including bioactivated MMC, the formaldehyde during MMC bio-reductive metabolism, and the doxoform from the reaction of the formaldehyde and DOX. The formaldehyde also depletes GSH by the formation of inactive GSH-formaldehyde conjugates, leading to increased intracellular DOX concentration. DOX enters the nucleus to inhibit the progression of $\mathrm{TII}_{\alpha}$ by forming the $\mathrm{TII}_{\alpha}$-DOX-DNA complex. The significant increased DNA crosslinking adducts during the DOX-MMC treatment triggers the activation of DNA repair system, which in turn promotes their collision with stalled TII, leading to enhanced DNA double strand breaks. (B) Pharmacokinetics and bio-distribution of DMPLN in orthotopic EMT6 murine breast tumor model. (i) DOX and MMC concentrations in whole blood as a function of time; (ii) Comparison of total DOX and MMC tumor accumulation between the free DOX-MMC combination and DMPLN; (iii) Percent of positive caspase-3 staining area in the breast tumor area $24 \mathrm{~h}$ and $48 \mathrm{~h}$ post-injection. ${ }^{*}$ and ${ }^{* *}$ indicates statistically significant difference between the DMPLN group and the other groups with $P<0.05, P<0.01$ or $P<0.005$, respectively. All data are mean \pm standard error of the mean (SEM) $(n=3)$. Figure $2 \mathrm{~A}$ is adapted from Shuhendler et $\mathrm{a}{ }^{[66]}$ and Figure $2 \mathrm{~B}$ is reproduced from Zhang et al ${ }^{[36]}$ with permission. 
A

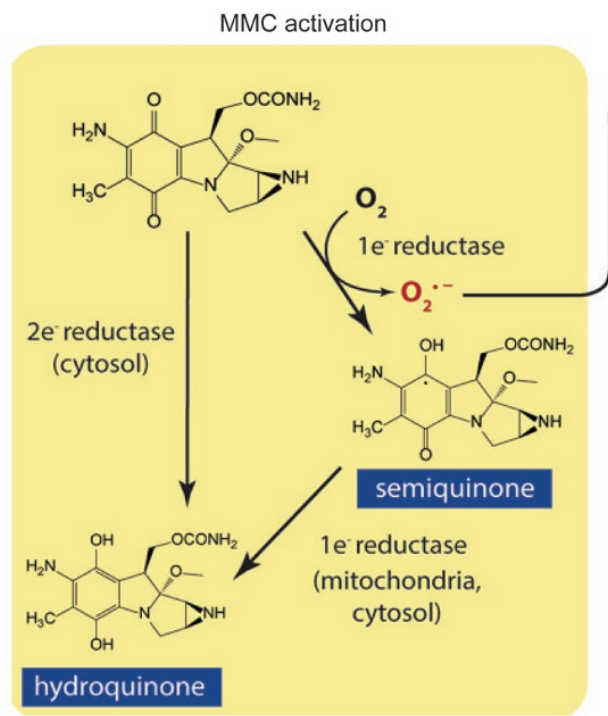

ROS generation by Fenton/Haber-Weiss pathway

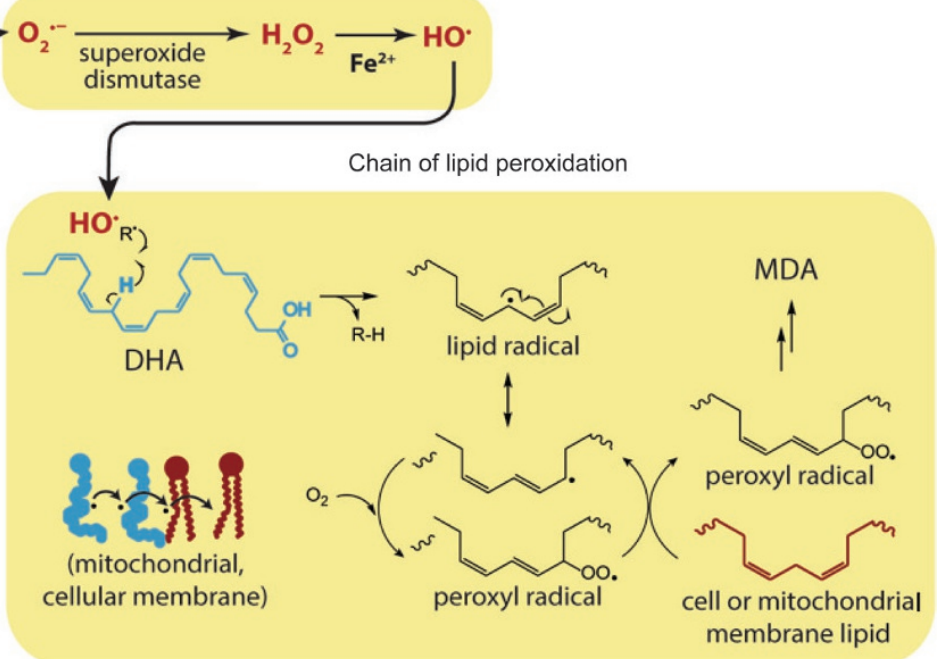

B (i)

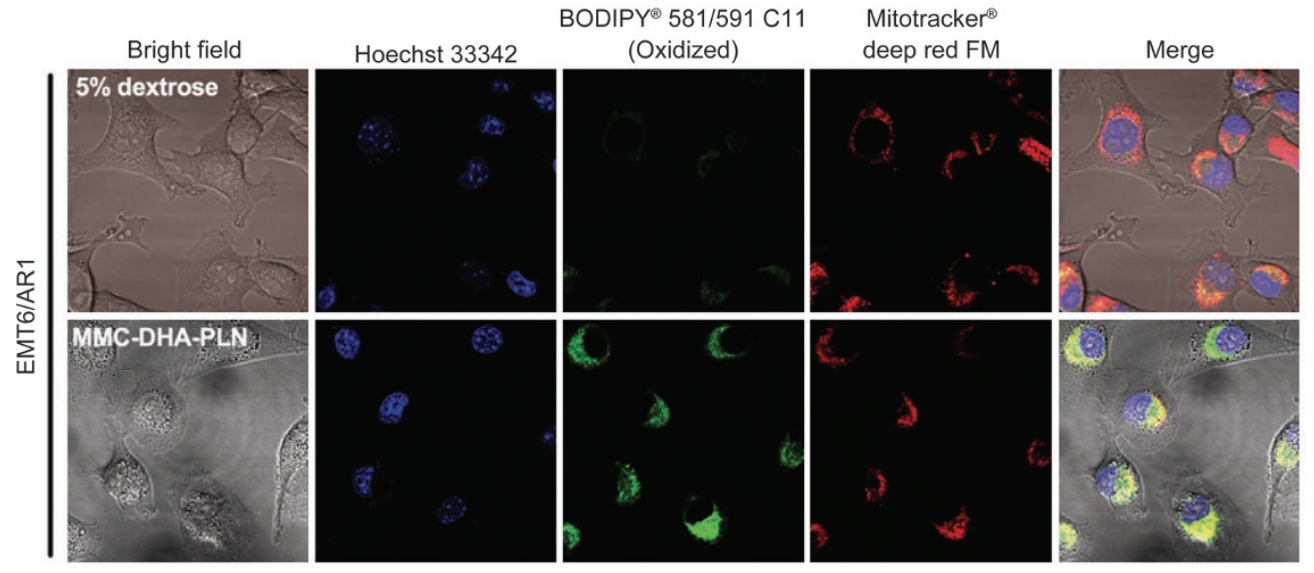

(ii)

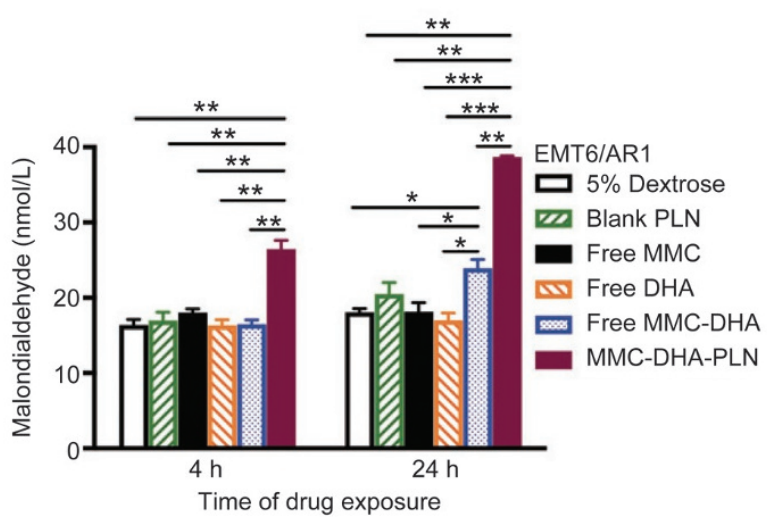

(iii)

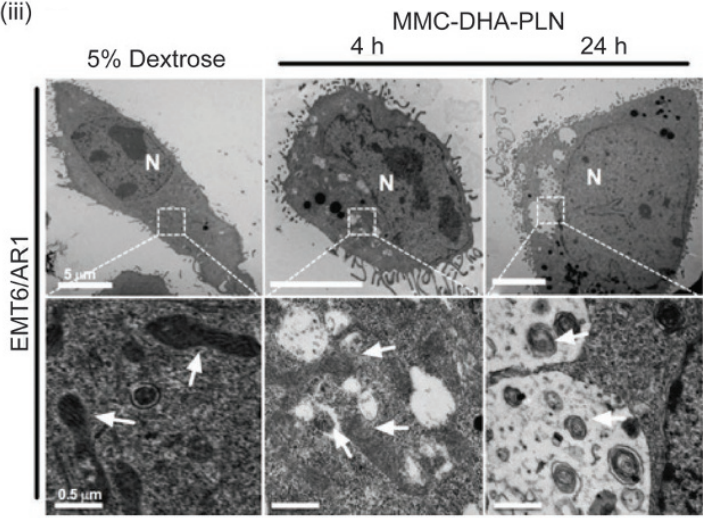

Figure 3. Mitochondrial enzymes triggered in situ lipid peroxidation of synergistic MMC-DHA combination and their sequential targeting capability using MMC-DHA-PLN. (A) Reaction schemes showing the cascade of lipid peroxidation produced by MMC-DHA combination that elevates intracellular oxidative stress. Activation of MMC through one-electron bio-reduction by mitochondrial enzymes generates the free radical, superoxide $\left(\mathrm{O}_{2}{ }^{-}\right)$, which in turn is converted to the hydroxyl radical $(\mathrm{HO})$ to attack the methylene bridge between $\mathrm{C}=\mathrm{C}$ double bonds of $\mathrm{DHA}$, leading to a chain of lipid peroxidation. ( $\mathrm{B}$ ) MMC-DHA-PLN targeted mitochondrial lipid peroxidation and induced irreversible ultra-structural damages to mitochondria in MDR EMT6/AR1 murine breast cancer cells with high expression of P-gp and rigid cell membrane. (i) Laser confocal microscope images of lipid peroxidation localization (green fluorescence) in mitochondria (red fluorescence) of cells treated with 5\% dextrose and MMC-DHA-PLN; (ii) The level of MDA before and after various free MMC and/or DHA formulations, blank PLN or MMC-DHA-PLN for $4 \mathrm{~h}$ or $24 \mathrm{~h}$; (iii) Transmission electron microscopy images of drug-resistant cells treated with $5 \%$ dextrose and MMC-DHA-PLN for $4 \mathrm{~h}$ and $24 \mathrm{~h}$. All data are means \pm SEM $(n=3-4)$ with ${ }^{*} P<0.05,{ }^{* *} P<0.01$, and ${ }^{* * *} P<0.001$. The figures are adapted and reproduced from Zhang et al ${ }^{[78]}$ with permission. 
a) Exploiting systemic circulation to design lung metastasistargeted RGD nanoparticles

Lung metastasis is common in several types of advanced cancers, including breast cancer, and is often associated with low patient survival ${ }^{[89,90]}$. In particular, for metastatic triplenegative breast cancer (TNBC), which lacks target receptors of estrogen, progesterone and human epidermal growth factor, the prognosis is poor, as hormonal and targeted therapies are not available and chemotherapy is ineffective in the late stages of the disease despite an initial response ${ }^{[90-92]}$. In light of the overexpression of the integrin $\alpha_{v} \beta_{3}$ receptors on the tumor neovasculature and many types of cancer cells, including TNBC cells ${ }^{[93,94]}$, the natural targeting ligand sequence Arg-GlyAsp (RGD) peptide was grafted on the surface of nanocarriers for targeted delivery of anticancer drugs to the tumor ${ }^{[95]}$. However, our early attempt to increase the accumulation of RGD-conjugated solid lipid nanoparticles (SLNs) in primary TNBC revealed significantly reduced tumor penetration and increased liver uptake compared to non-targeted NPs despite prolonged SLN retention time in the tumor ${ }^{[21]}$. Optimization of RGD density on the surface of NPs only modestly improved the NP accumulation in the solid tumor ${ }^{[96]}$. This observation is similar to other group's studies showing that introduction of RGD as a targeting moiety may increase the host immunogenicity and protein adsorption (eg, opsonin), leading to unwanted adverse effects and pronounced hepatic uptake ${ }^{[29,97]}$.

Unlike the cases of primary breast tumor where intravenous (iv) administered RGD-conjugated NPs and the payload therein are first removed by the liver and the spleen before reaching the breast, NP transport to the lungs occurs before the passage through the liver and spleen via naturally endowed systemic circulation. Following the direction of blood circulation, the iv administered NPs first enter the tumor-bearing lungs before the "first-pass effect" of liver clearance (Figure 4A). This is particularly advantageous for improving the delivery of the ligand-conjugated NPs as chemotherapeutics to the diseased sites in the lungs ${ }^{[98]}$. Based on the physiological characteristics of both systemic and pulmonary circulation, we have optimized an RGD-conjugated PLN system (RGD-PLN) so that it can highly accumulate in TNBC metastasis-bearing lungs ${ }^{[98]}$. Upon arrival at the highly vascularized networks of the lungs, the RGD-PLN bind to the $\alpha_{v} \beta_{3}$ integrin receptors overexpressed on both the tumor cells and the angiogenic blood vessels near metastatic tumor modules (Figure 4B). This design concept was proven viable by microscopic examination of the tumor area, which depicted much higher accumulation of RGD-PLN than the non-targeted PLN in both the tumor vasculature and metastatic tumor cells (Figure 4C). Consequently, RGD-PLN co-loaded with DOX and MMC (RGD-DMPLN) significantly reduced the metastatic burden and extended the median survival time in a lung metastasis model compared to a non-targeted DMPLN (Figure $4 \mathrm{D} \& \mathrm{E})$. It is worth noting that off-target binding of RGD-PLN could occur during circulation due to the abundant expression of integrin receptors such as $\alpha_{v} \beta_{3}$ receptors on the macrophage and human endothelial cells ${ }^{[99-101]}$. Thus, exploitation of the systemic circulation direction can potentially minimize such off-target effects, as iv-administered RGD-PLN reaches the disease site at the lungs first and binds to the tumor neovasculature and tumor cells that overexpress integrin $\alpha_{v} \beta_{3}$ receptors.

\section{b) Harnessing naturally occurring lipoprotein to design self- decorating nanoparticles for drug delivery to the brain}

Nearly $15 \%-30 \%$ of patients with advanced breast cancer develop brain metastases during progression of the disease $\mathrm{e}^{[102,103]}$. Brain metastases are associated not only with a poor prognosis but also with severe neurological impairment ${ }^{[102,103]}$. The treatment of brain metastases is challenging due to the inability of most therapeutic agents to penetrate the $\mathrm{BBB}$, leading to subtherapeutic drug accumulation in the $\mathrm{CNS}^{[102-104]}$. The BBB consists of a continuous layer of tight junction-expressing endothelial cells and presents a highly selective biological barrier. The drug efflux transporters (eg, P-gp, multidrug resistance-associated proteins (MRPs), and breast cancer resistance protein (BCRP)) found on brain endothelial cell membranes further expel substrate molecules, including many effective anticancer drugs (eg, DOX), from the brain ${ }^{[105-107]}$. As a result, it restricts passive entry of nearly $98 \%$ of all drugs to the brain at the blood-brain interface ${ }^{[105-107]}$. Therefore, development of effective strategies for shuttling drugs across the BBB has been a long-standing goal in the drug delivery field.

Various non-invasive strategies have been investigated for delivering therapeutic agents into the brain ${ }^{[106,108-110]}$. The examples include utilization of ligands for overexpressed receptors on the BBB (eg, transferrin, insulin, low-density lipoprotein (LDL), and Angiopep-2), of essential nutritive compounds required for cell metabolism and survival of the CNS (eg, glutathione, choline, glucose), or of cationic peptides that electrostatically interact with the negatively charged brain microvessel endothelial cells ${ }^{[106,108-12]}$. Among these strategies, the receptor-mediated transport appears to be the most favorable due to the specificity of ligand-receptor interactions. Monoclonal and single-domain antibodies have been developed for various endogenous BBB transcytosis receptors (eg, receptors for insulin and transferrin) ${ }^{[111,113-117]}$. However, the antibody approach suffers from high cost and the potential host immunogenic response ${ }^{[118]}$.

Of the various receptor-mediated brain-penetrating systems, NPs present more advantages than antibody-drug conjugates (ADC), bispecific antibodies, and fusion proteins because of their easy manufacture, low cost, high loading capacity, flexibility of encapsulating various cargos, and controllable drug release kinetics ${ }^{[36,107,119-121]}$. Nanoparticle carriers can be engineered by surface decoration of targeting antibodies or ligands via covalent bonds or physical coating ${ }^{[10,119]}$. Compared to pre-engineered nanocarrier systems, NPs that are able to adsorb receptor-binding moieties from the blood during circulationare more attractive owing to their low immunogenicity and cost effectiveness.

We have designed a platform nanoparticle system based on a terpolymer consisting of a starch backbone and grafted 
A

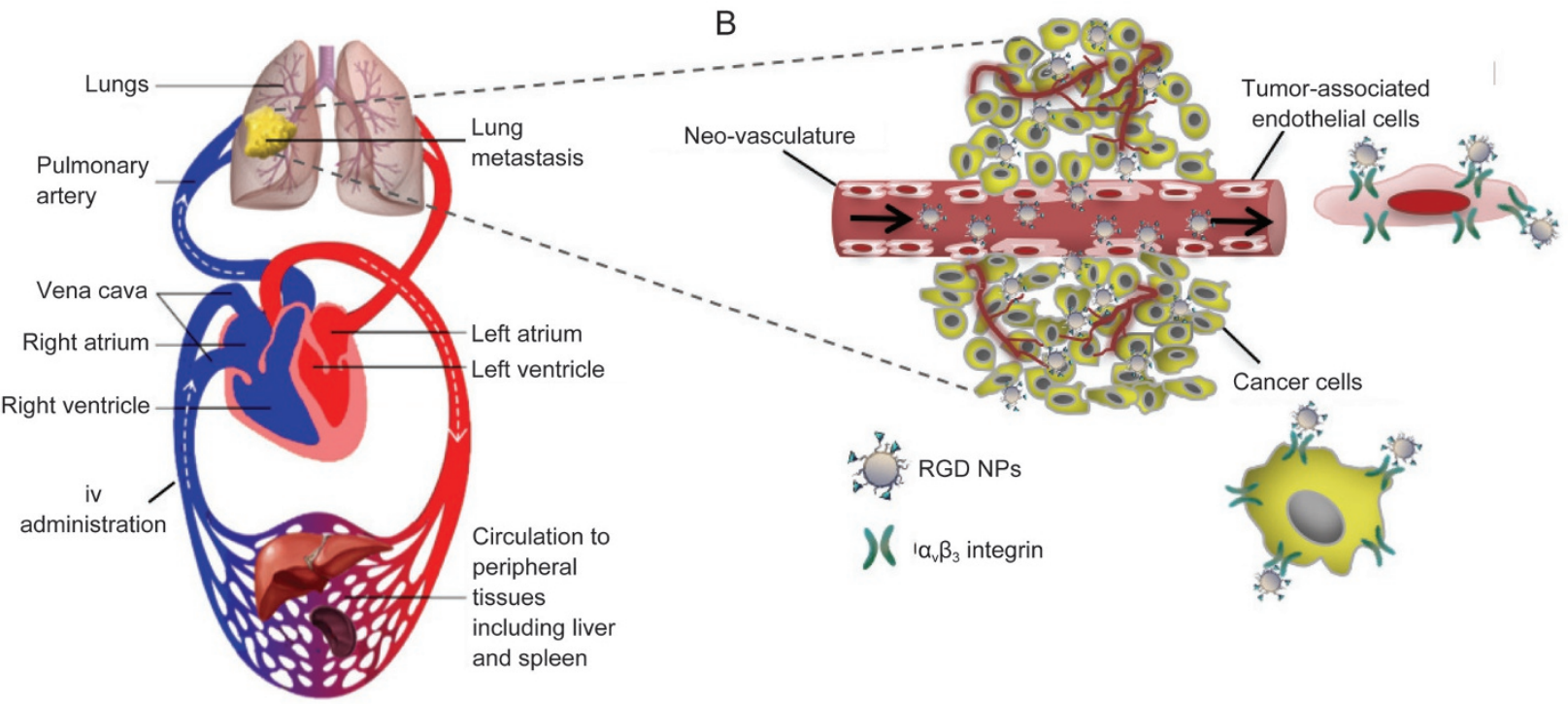

C

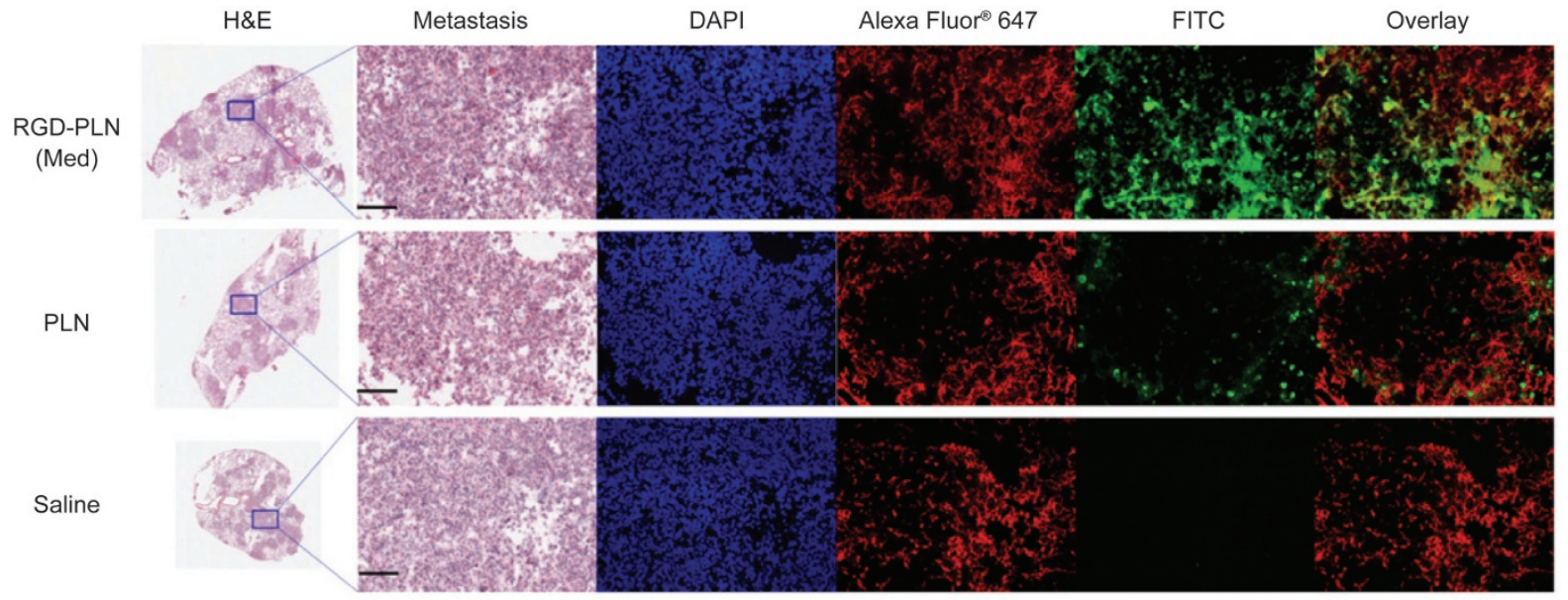

D

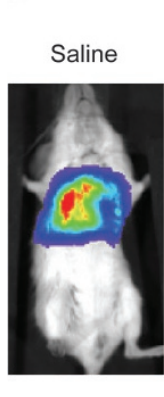

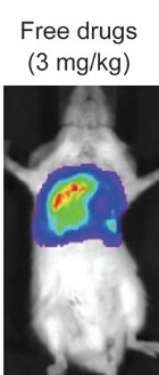

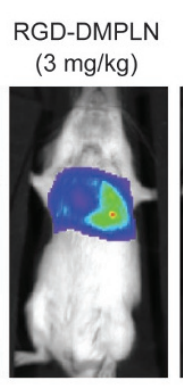

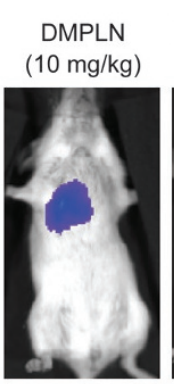

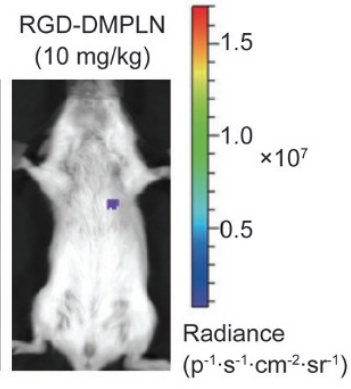

E

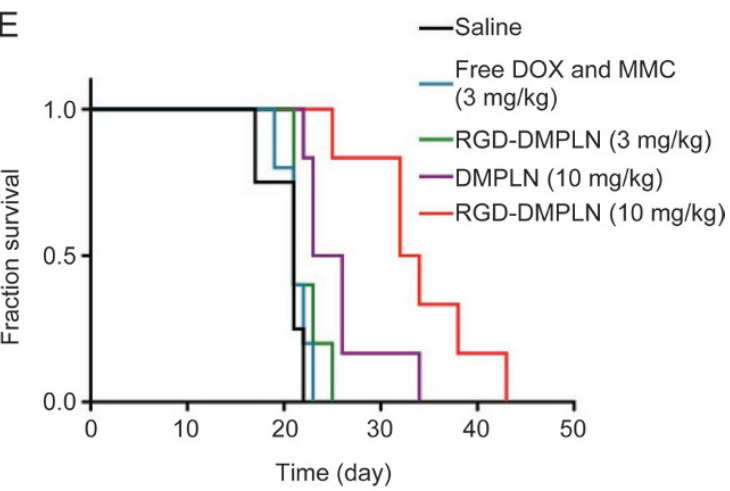

Figure 4. Exploiting the physiology of circulatory system to design lung metastasis-targeted RGD-NPs. (A) The flow direction of the blood circulation. The human cardiovascular system consists of pulmonary and systemic circulation components. The iv administrated NPs enter the veinous circulation and then follow the direction of blood flow (white arrows) to reach the lungs before arriving at clearance organs, such as the liver and spleen. (B) Once reaching the lungs, RGD-PLN targeted both tumor neo-vasculatures and cancer cells that overexpress $\alpha_{v} \beta_{3}$ integrin receptors. (C) Confocal fluorescence microscopic images of the metastasis-bearing lungs inoculated with MDA-MB-231-IUc-D3H2LN human TNBC cells in SCID mice $4 \mathrm{~h}$ post iv injection of optimized RGD-PLN, non-targeted PLN or saline. Transverse sections of the lung were made and metastatic tumor nodules appear purple under H\&E staining. The zoomed tumor area was stained with DAPI for nuclei (blue) and Alexa Fluor ${ }^{\circledR} 647$ labelled CD-31 antibody for blood vessels (red) and FITC for FITC-labeled NPs (green). Scale bar: $200 \mu \mathrm{m}$ for all zoomed images. (D) In vivo bio-luminescent images of mice treated with free DOX-MMC solution, DMPLN and RGD-DMPLN at two dose regimens on the day $28^{\text {th }}$ after the initial tumor inoculation. (E) Kaplan-Meier plot of the tumor-bearing mice for all groups. RGD-DMPLN improved the survival of lung metastasis-bearing mice compared to free DOX-MMC in solution and non-targeted DMPLN. Figure $4 \mathrm{C}, 4 \mathrm{D}$ and $4 \mathrm{E}$ are reproduced by Zhang et $\mathrm{I}^{[98]}$ with permission. 
poly(methacrylic acid) and polysorbate 80 (PS 80) ${ }^{[122-124]}$. An in vitro binding assay showed good binding affinity of the terpolymer NPs to recombinant human ApoE protein. It has been demonstrated that the PS 80 chains protruding on the nanoparticle surface can recruit apolipoproteins (eg, Apolipoprotein $\mathrm{E}(\mathrm{ApoE}))$ in the plasma upon iv administration and then be transcytosed via low density lipoprotein receptor (LDLR) recognition to enter the brain parenchymal side (Figure 5A) ${ }^{[125-127]}$. The abundant hydroxyl and carboxylic acid groups present on starch and methacrylic acid enable easy chemical modification and the loading of a wide variety of BBB-impermeable agents with different physicochemical properties, including a magnetic resonance imaging (MRI) contrast agent $^{[124]}$, fluorescence dyes ${ }^{[128,129]}$, the hydrophilic anti-cancer drug DOX ${ }^{[128,129]}$, the hydrophobic drug docetaxel (DTX ${ }^{[130]}$ and the therapeutic antibody trastuzumab (TRA) ${ }^{[131]}$.

DOX-encapsulated terpolymer NPs accumulated in the brain metastasis area via transcytosis and the EPR effect (Figure 5B) and inhibited tumor growth (Figure 5C) ${ }^{[128]}$. The terpolymer was also modified and combined with a lipid to form a nanoparticle formulation of DTX (DTX-NP). Compared to clinically used solution form of DTX (Taxotere ${ }^{\circledR}$ ), DTX-NP delivered a larger amount of DTX to the brain (Figure 5D) and exerted a greater therapeutic effect in a brain metastasis model (Figure 5E ${ }^{[130]}$. Delivery of a therapeutic antibody to the brain requires particular considerations differing from the delivery of small molecules. To deliver therapeutic antibody TRA to human epidermal growth factor receptor-2 (HER2)-positive cancer cells in the brain metastasis area, we developed an intracellularly eroded solid-lipid polymer matrix containing a TRA-conjugated terpolymer. The nanoconstructs were able to shield TRA in the circulatory system and deliver it to brain tumors via a two-step targeting process ${ }^{[131]}$. The constructs remained intact during systemic circulation, crossed the BBB (ie, the first step in targeting the brain), and then $\mathrm{n}$ dissociated and exposed TRA, enabling the second-step targeting of TRA to the cancer cells within the brain and thus generating a therapeutic effect ${ }^{[131]}$. Such a self-decorating platform nanosystem exhibits versatile drug delivery capabilities and a tremendous potential for the rational design of non-invasive nanotechnology-based treatments of various brain disorders.

\section{Integration of nanotechnology with pathophysiological features for disease-responsive drug delivery and enhanced radiation therapy}

Pathophysiological characteristics, such as hypoxia in the TME and unregulated hyperglycemia in diabetes, are distinct from normal physiological conditions. In this section, we describe the design and first application of clinically relevant, bioreactive hybrid manganese dioxide $\left(\mathrm{MnO}_{2}\right) \mathrm{NPs}$ to modulate multiple pathological factors in the TME for improving radiation therapy. We also present a nanotechnologyenabled closed-loop insulin delivery system that utilizes a stimuli-responsive nanohydrogel and $\mathrm{MnO}_{2} \mathrm{NPs}$ (MDNPs) to mimic normal endocrinology for regulating insulin release in response to pathophysiological conditions of hyperglycemia in a timely self-regulated manner.

a) Tackling pathological factors of the tumor microenvironment using bio-reactive hybrid MDNPs to sensitize cancer cells to radiation therapy

The abnormal TME manifests itself by several major hallmarks, including hypoxia, overexpression of hypoxiaregulated genes, acidosis, and ROS generation ${ }^{[132-135]}$, among which hypoxia is a poor prognostic factor implicated in tumor resistance to mainline treatments, eg, radiotherapy $(\mathrm{RT})^{[136,137]}$ and chemotherapy ${ }^{[33]}$. For RT, the presence of $\mathrm{O}_{2}$ enhances the production of DNA double-strand breaks in cancer cells and permanently "fixes" DNA damage caused by direct ionization or water radicals into a more difficult - to repair state ${ }^{[137,138]}$. However, the hypoxia found in many solid tumors directly hinders this mechanism, resulting in the reduced efficacy of RT (eg, decreased DNA double-strand breaks $)^{[137,139]}$. Moreover, hypoxia and ROS lead to overexpression of hypoxia-inducible factor-1a (HIF-1a), a master regulator of many downstream genes and proteins ${ }^{[140-144]}$, such as vascular endothelial growth factor $(\mathrm{VEGF})^{[145,146]}$ and carbonic anhydrase IX $(\mathrm{CAIX})^{[132,147]}$. All of these pathological factors contribute to locally increased oxidative stress ${ }^{[148,149]}$, acidosis ${ }^{[150,151]}$, angiogenesis ${ }^{[142]}$, cancer cell proliferation and metastasis ${ }^{[134]}$, leading to poor patient prognosis (Figure 6A (i)).

Various nanotechnology-based strategies have been developed to modulate TME, including 1) nanoparticle formulations of angiogenesis inhibitors or small interfering RNA (siRNA) against vascular endothelial growth factor receptor-2 (VEGFR-2) to remodel the tumor vasculature, 2) compounds for reducing/degrading collagen content in the tumor extracellular matrix, and 3) cytokines to modulate the phenotype of tumor-associated macrophages $(\mathrm{TAMs})^{[134]}$. Given the multiple pathological factors of the TME and their pleiotropic effects on poor therapeutic outcomes, our laboratory has developed clinically suitable bio-reactive MDNP formulations and applied them for the first time to attenuate several negative features of the TME simultaneously ie, hypoxia, acidosis, and ROS generation (eg, excessive hydrogen peroxide $\left(\mathrm{H}_{2} \mathrm{O}_{2}\right)$ ) (Figure 6A(i) $)^{[152-154]}$. Through a simple catalytic chemical reaction at the pathological $\mathrm{pH}(\sim 6.8)$ of the TME, the MDNPs can sustainably convert excess $\mathrm{H}_{2} \mathrm{O}_{2}$ and protons $\left(\mathrm{H}^{+}\right)$into $\mathrm{O}_{2}$, leading to reduction in hypoxia, oxidative stress and acidity in the TME ${ }^{[152,154]}$. The $\mathrm{pH}$ - and $\mathrm{H}_{2} \mathrm{O}_{2}$ concentration-dependent reactivity endows the MDNPs with a tumor-selective function due to the higher physiological pH ( 7.4) and lower ROS level in the systemic circulation and in normal tissue ${ }^{[152,154]}$. The in situ oxygenation by MDNPs mitigates the hypoxia of TME, which in turn attenuates tumor-promoting factors and overcomes hypoxia-induced radio-resistance, thereby enhancing the efficacy of RT (Figure 6A(ii)).

A new iv injectable formulation of MDNPs was developed by incorporating $\mathrm{MnO}_{2}$ into a lipid matrix with a polymer corona to improve biocompatibility and bio-distribution, thereby helping protect the MDNPs during their systemic circulation and enabling their passive accumulation in the solid 

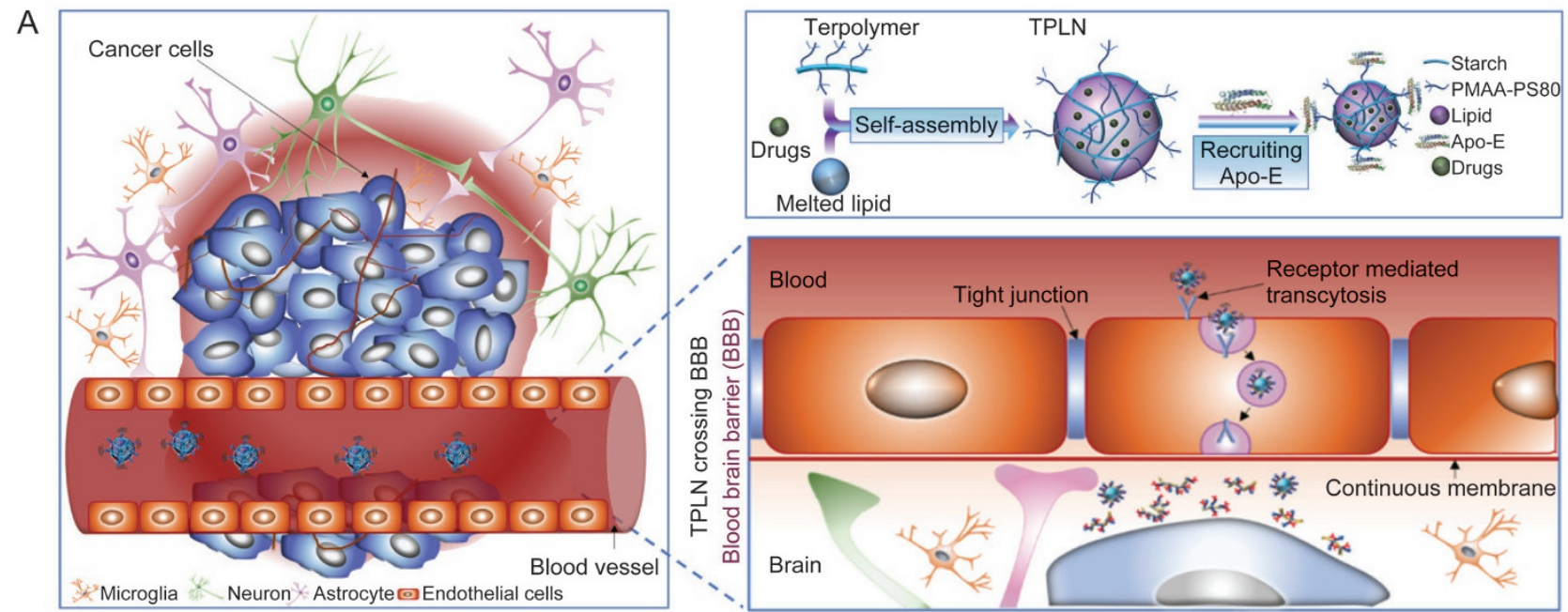

B (i)

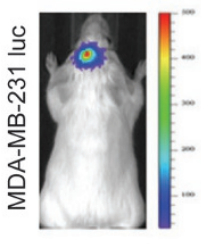

(iii) MDA-MB-231 luc cell Bioluminescence

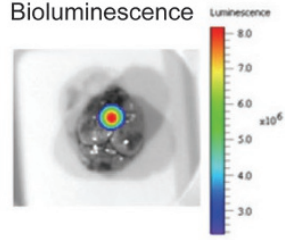

D

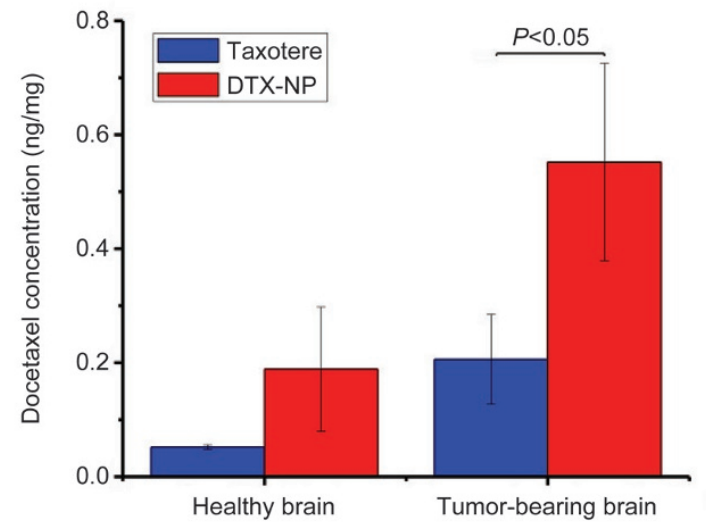

(ii) Baseline $15 \mathrm{~min} 30 \mathrm{~min}$

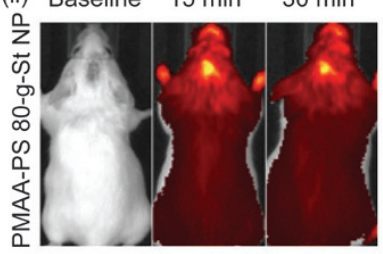

(iv) PMAA-PS 80-g-St NP Fluorescence

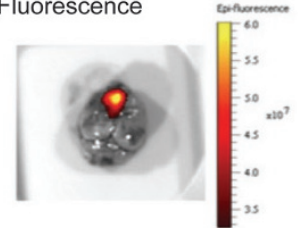

Brain

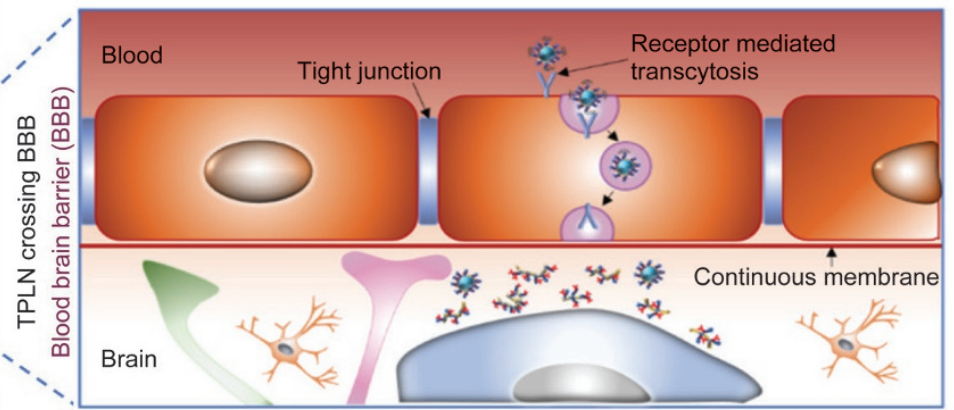

C

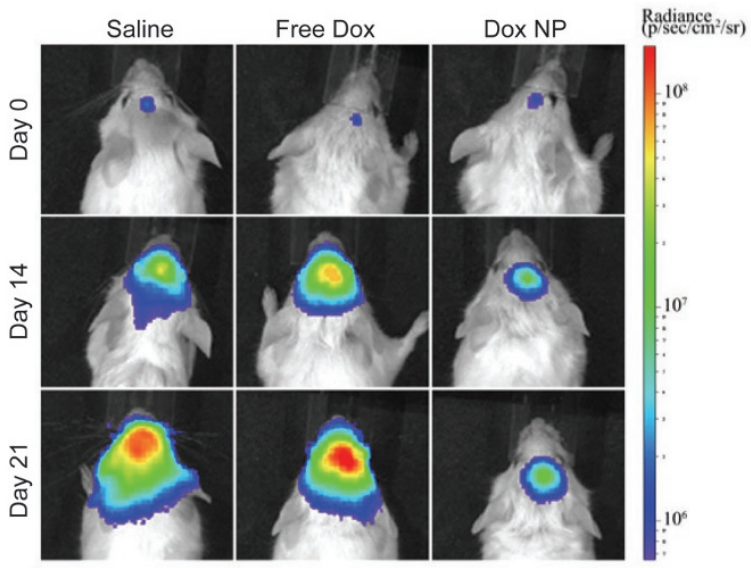

E

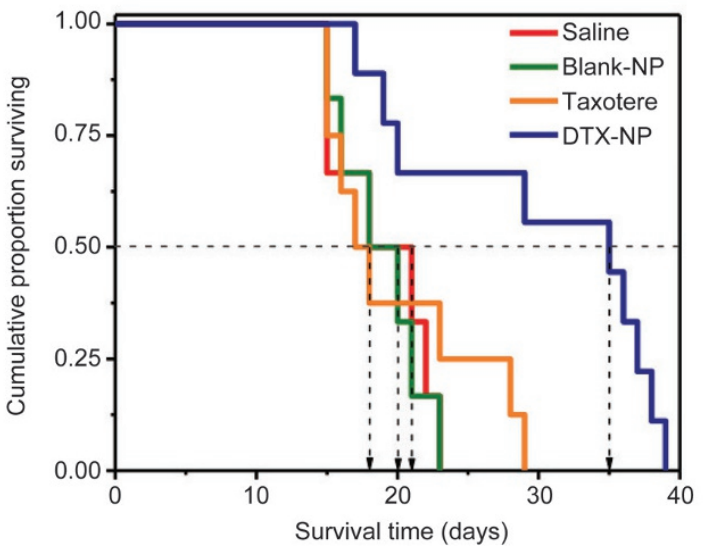

Figure 5. Harnessing the physiology of naturally occurring lipoprotein to design self-decorating terpolymer NPs or terpolymer-lipid hybrid NPs (TPLN) for drug delivery to the brain. (A) Schematic of the receptor-mediated transcytosis mechanism of PMAA-PS 80 (terpolymer)-containing polymeric NPs penetration through the BBB to deliver encapsulated drug to brain cancer cells. (B) In vivo bioluminescent images of brain tumors and optical wholebody and ex vivo images of brain accumulation of NP. The brain metastases of MDA-MB-231-IUc-D3H2LN cells in NRG-SCID mice were established by intracranial injection: (i) Bioluminescence of luciferase expressing tumor cells in the inoculated brain tumors 10 min following ip injection of luciferin solution; (ii) PMAA-PS 80-g-St NPs were labeled with a near infrared dye (HiLyte Fluor 750) and imaged after iv tail vein injection; (iii) Bioluminescent image of brain tumor; (iv) Fluorescence image of nanoparticles in an excised mouse brain. (C) In vivo images of brain tumor bioluminescence showing tumor growth inhibition in NRG-SCID mice. (D) Docetaxel (DTX) concentration in tumor-bearing brains at 15 min after iv injection of DTX-NP compared to Taxotere ${ }^{\circledR}$ (free DTX in solution). The concentration of DTX in the perfused brains of mice was quantified using LC-MS/MS following iv injection of DTXNP or Taxotere ${ }^{\circledR}$ at the dose of $20 \mathrm{mg} / \mathrm{kg}$ DTX. All data are mean \pm standard deviation (SD) ( $\left.n=3\right)$. (E) Kaplan-Meier survival curve of tumor-bearing mice following the treatment of saline, blank NP, Taxotere ${ }^{\circledR}(20 \mathrm{mg} / \mathrm{kg}$ DTX) or DTX-NP (20 mg/kg DTX). All data are mean \pm standard deviation (SD) ( $n=9)$. Figure 4B, 4C and Figure 4D, 4E are reproduced from Li et al ${ }^{[128]}$ and He et al ${ }^{[130]}$, respectively with permission. 
A (i)

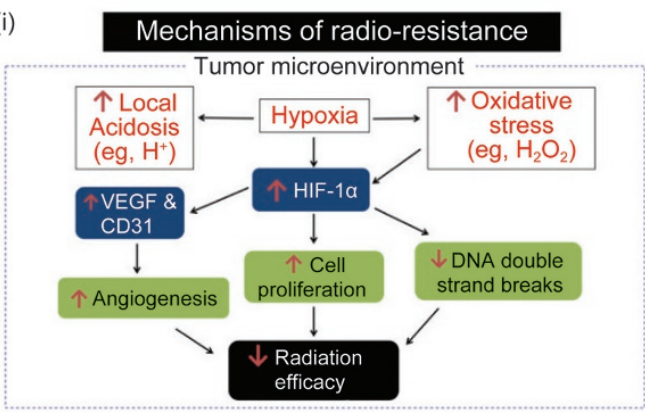

(ii) $\mathrm{MnO}_{2}+\mathrm{H}_{\mathrm{H}} \mathrm{O}_{2}+2 \mathrm{H}^{*} \rightarrow$ Manganese dioxide nanoparticles

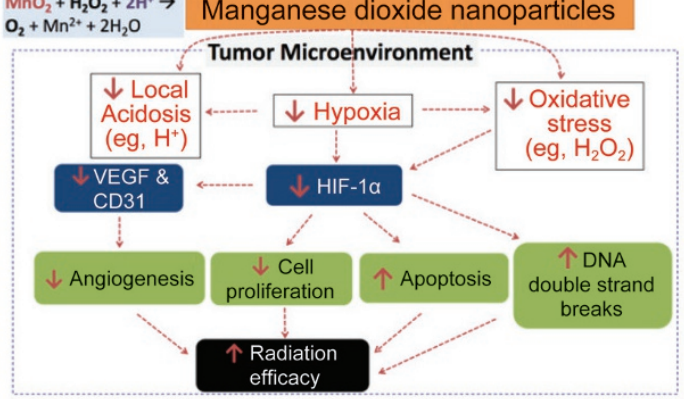

(ii)

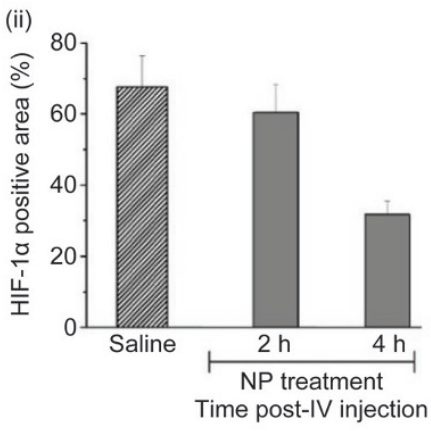

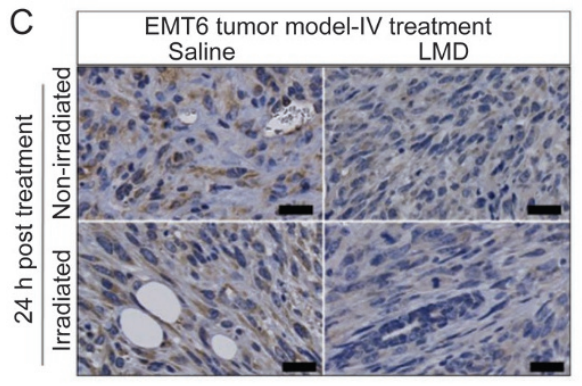
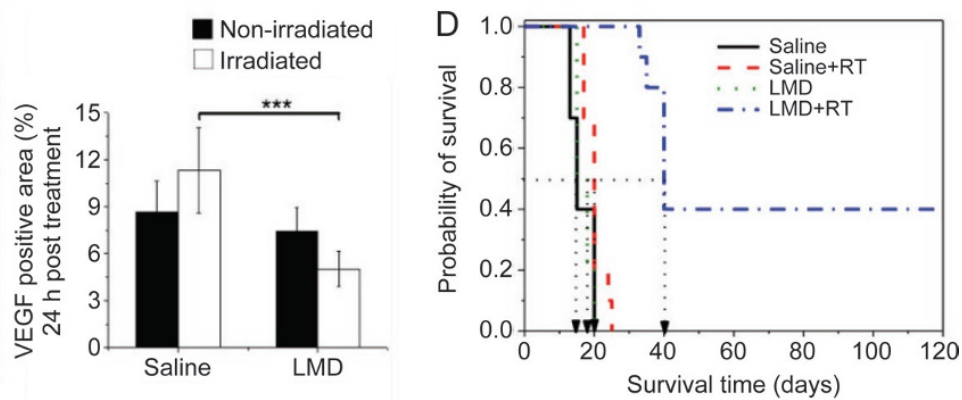

Figure 6. (A) (i) Scheme of TME-associated radiation resistance; (ii) Modulation of the TME by $\mathrm{MnO}_{2} \mathrm{NPs}_{\text {to }}$ enhance RT efficacy. Hypoxia characterized by low $\mathrm{O}_{2}$ levels in the TME contributes to up-regulation of HIF-1 $\alpha$, an important transcription factor that regulates the metabolism and proliferation of cancer cells and angiogenesis. Such low $\mathrm{O}_{2}$ levels reduce the mechanism of $\mathrm{O}_{2}$ enhanced cell killing by radiation therapy. $\mathrm{MnO}_{2} \mathrm{NPs}$ are able to decompose $\mathrm{H}_{2} \mathrm{O}_{2}$ (reduced oxidative stress) and scavenges $\mathrm{H}^{+}$(decreased local acidosis) to create a more favorite TME for cell killing by radiation therapy. (B) (i) Effect of iv treatment with LMD NPs on tumor hypoxia determined by pimonidazole analysis at $4 \mathrm{~h}$ after treatment; (ii) the hypoxia level in tumors for LMD or saline-treated animals at $2 \mathrm{~h}$ and $4 \mathrm{~h}$. The scattered points (orange dots) represent tumor hypoxia level of individual animal to identify the heterogeneity in tumor hypoxia among animals following LMD treatment. Scale bar, $1 \mathrm{~mm}$. Data show mean \pm SD ( $n=5$ for saline- and $n=10$ for LMD-treated group). (C) Effect of LMD NPs treatment alone or with radiation on tumor VEFG expression in breast tumor. Representative IHC staining for VEFG and corresponding quantification at $24 \mathrm{~h}$ after iv treatment. Scale bars: $25 \mu \mathrm{m}$ and data show mean SD ( $\mathrm{n}=3 / \mathrm{group}$ ). (D) Kaplan-Meier survival curves for all treatment groups. Horizontal dotted line is $50 \%$ survival level. $* * *$ indicates statistically significant difference with $P<0.001$. All in vivo experiments were performed in female BALB/c mice orthotopic implanted with EMT6 murine breast cancer cells. Figure 5B, 5C, 5D are reproduced from Abbasi et al ${ }^{[155]}$ with permission.

tumor via the EPR effect ${ }^{[3,152,155]}$. Preclinical studies using orthotopic breast tumor models demonstrated good tumor accumulation and sustained effects of the lipid-polymer-based MDNPS (LMD NPs) on modulating TME factors, ie, hypoxia and HIF-1a and VEGF expression (Figure $6 \mathrm{~B} \& \mathrm{C}$ ) ${ }^{[152,155]}$. The optimal time interval post iv injection of the LMD NPs was identified as $4 \mathrm{~h}$, at which point intra-tumoral oxygenation reached a maximum (Figure $6 \mathrm{~B})^{[152,155]}$. This time interval was then selected for the application of ionizing radiation to treat breast tumors following iv injection of the LDMN NPs. The in situ effect of the LMD NPs was so powerful that a single pretreatment with LMD NPs followed by 10 Gy local irradiation of the tumor led to profound improvement in response to RT. Compared to RT alone, which essentially exhibited no inhibitory effect on tumor growth in this hypoxic breast tumor model, the combination of LMD NPs with RT strikingly prolonged the median survival time by $500 \%$ and resulted in a $40 \%$ cure rate (Figure 6D) ${ }^{[152,154,155]}$. Our recent studies on combination therapy with MDNPs and chemotherapy (ie, DOX) demonstrated that pretreatment with MDNPs also signifi- 
cantly enhanced the efficacy of chemotherapy and antitumor immunity ${ }^{[156]}$. These findings suggest potential broader clinical applications for the modification of TME factors to enhance the effectiveness of cancer treatments.

b) Mimicking dynamic insulin release from human pancreatic $\beta$-cells by utilizing a fast responsive nanogel and self- $\mathrm{O}_{2}$ replenishing MDNPs for tight glucose control

Type 1 diabetes mellitus (T1D) is a metabolic disorder affecting more than 347 million people globally ${ }^{[157]}$. In T1D patients, insulin-producing pancreatic $\beta$-cells are damaged, and these patients rely on multiple administrations daily of exogenous insulin to sustain their lives ${ }^{[158,159]}$. Insulin is a key hormone regulator of glucose metabolism that decreases blood glucose levels to maintain them below $5.6-6 \mathrm{mmol} / \mathrm{L}(\sim 100 \mathrm{mg} / \mathrm{dL})$ (Figure $7 \mathrm{~A})^{[160]}$. In healthy individuals, insulin secretion by pancreatic $\beta$-cells is synchronized with glucose level via a quick pulsatile surge when the glucose level rises after a meal and brings it down to euglycemia within $30-60 \mathrm{~min}^{[161,162]}$ (Figure 7A).

Mimicking this dynamic insulin release pattern is critical to avoid extended tissue exposure to hyperglycemia and the risk of hypoglycemia. However, even with frequent self-monitoring of glucose level and administration of anticipated amounts of insulin, conventional insulin therapy is far from the ideal physiological response ${ }^{[163-165]}$. Therefore, closed-loop insulin delivery systems have been developed to automate these steps with the use of continuous blood glucose monitors and insulin pumps to better emulate physiological conditions and minimize user's intervention (Figure 7B). However, the cost of the pumps and accessories and the short usage duration (3-7 d) of the accessories remain to be resolved ${ }^{[166,167]}$.

Recent advances in nanomaterials offer new opportunities for developing next-generation closed-loop insulin delivery systems that better mimic the endocrinological secretion of insulin ${ }^{[9]}$. Our laboratory introduced $\mathrm{pH}$-responsive hydrogel NPs to replicate the rapid and dynamic insulin release at physiologically relevant time scales ${ }^{[168-174]}$. The hydrogel NPs, embedded in a pH-insensitive polymer membrane (Figure 7C), undergo a volume-phase transition from a swollen state at physiological $\mathrm{pH}$ to a collapsed state at acidic $\mathrm{pH}$ below their $\mathrm{pK}_{\mathrm{a}}{ }^{[175,176]}$. When combined with glucose oxidase (GOx), the $\mathrm{pH}$-responsive nanogels shrink in response to decreased local $\mathrm{pH}$ due to the production of gluconic acid from the catalyzed glucose oxidation. The glucose-responsive volume change of the nanogels regulates the permeability of the composite membrane and thus controls the rate of insulin release from the reservoirs (Figure 7D) ${ }^{[168-174]}$.

The nanometer-sized hydrogel is a key component imparting a short response time to the composite membranes. Reduction in the dimensions of a material from millimeters to nanometers dramatically decreases analyte diffusion distance (Figure 7C). Consequently, it will take a much shorter time for nanogel to reach volume change equilibrium, as diffusion time scales with the square of diffusion distance $t=x^{2} / q D$ where $x$ is the mean diffusion distance, $\mathrm{D}$ is the diffusion coefficient, $\mathrm{t}$ is the diffusion time, and $\mathrm{q}$ is a dimensionality constant $)^{[177,178]}$. For example, for a solvent molecule $\left(e g, \mathrm{H}_{2} \mathrm{O}\right)$ with $\mathrm{D}=10^{-6}$ $\mathrm{cm}^{2} / \mathrm{s}$, diffusion over a $1 \mathrm{~mm}$ distance will take $10000 \mathrm{~s}(2.8 \mathrm{~h})$, while in a nanogel with characteristic dimensions of $100 \mathrm{~nm}$, it will take $10^{-4} \mathrm{~s}$ (Figure $7 \mathrm{C}$ ). In this way, the $\mathrm{pH}$-responsive NPs (150-300 nm) embedded in the membrane would change their volume in response to a glucose-converted $\mathrm{pH}$ signal within a fraction of second. As a result, the alteration of insulin release rate across the membrane can occur within seconds after a step change in environmental glucose concentration in vitro (Figure 7D) $)^{[168,171]}$.

A common and long-standing problem in biosensors that utilize a glucose oxidation-produced signal to detect glucose level is the insufficient $\mathrm{O}_{2}$ supply in vivo. In a small confined subcutaneous tissue where a sensor is placed, $\mathrm{O}_{2}$ level is not proportional to glucose concentration, especially in the state of hyperglycemia. Although catalase is incorporated in some devices to recover consumed $\mathrm{O}_{2}$, it can only convert half of the byproduct $\mathrm{H}_{2} \mathrm{O}_{2}$ back to $\mathrm{O}_{2}$. To solve this problem, we introduced MDNPs in the composite membrane to continuously catalyze the breakdown of $\mathrm{H}_{2} \mathrm{O}_{2}$ to molecular $\mathrm{O}_{2}$ and water at a one-to-one molar ratio $\left(\mathrm{H}_{2} \mathrm{O}_{2}+2 \mathrm{H}^{+}{ }_{-}{ }^{\mathrm{MnO} 2}----\mathrm{O}_{2}+2 \mathrm{H}_{2} \mathrm{O}\right)$ (Figure 7D) ${ }^{[169,172,173]}$. In this way, the incorporated MDNPs not only reduced the enzyme-damaging $\mathrm{H}_{2} \mathrm{O}_{2}$, a by-product of glucose oxidation, preserving the enzymatic activity of GOx and catalase, but also raised the microdomain $\mathrm{pH}$, avoiding over-acidification at low glucose concentration ${ }^{[172,179]}$. As a result, the engineered MDNP-containing GOx-based closedloop insulin delivery system was able to provide rapid stepwise pulsatile insulin release at pathophysiologically relevant changes in glucose concentration (eg, from 100 to 200, to 400 $\mathrm{mg} / \mathrm{dL}$ ) and long-term GOx stability compared to systems without MDNPs ${ }^{[172,179]}$. After implantation in T1D rats, this nanotechnology-enabled insulin delivery system was able to reproducibly bring elevated blood glucose levels down to normal levels within $30 \mathrm{~min}$ after induced hyperglycemia, which mimics the endogenous insulin response time of healthy rats (Figure 7E) and resembles the pattern in healthy humans (Fig-

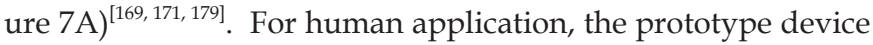
needs to be scaled up according to the body size ratio and required insulin dose and be refillable with insulin solution for repeated administration. Nevertheless, these results suggest that the design and testing of nanotechnology-based drug delivery systems should be guided tightly by the diseaseassociated pathophysiology. In other words, the medical application of a drug delivery system should be understood thoroughly before investing time and finance in engineering tasks.

\section{Conclusions and future perspectives}

The ultimate goal of nanotechnology-enabled drug delivery systems in the clinic is to improve patient survival and quality of life. This review has emphasized the convergence of nanotechnology, pharmacology and physiology in the rational design of effective drug delivery systems. To design clinically translatable nanomedicine for cancer therapy, it is important to 
A

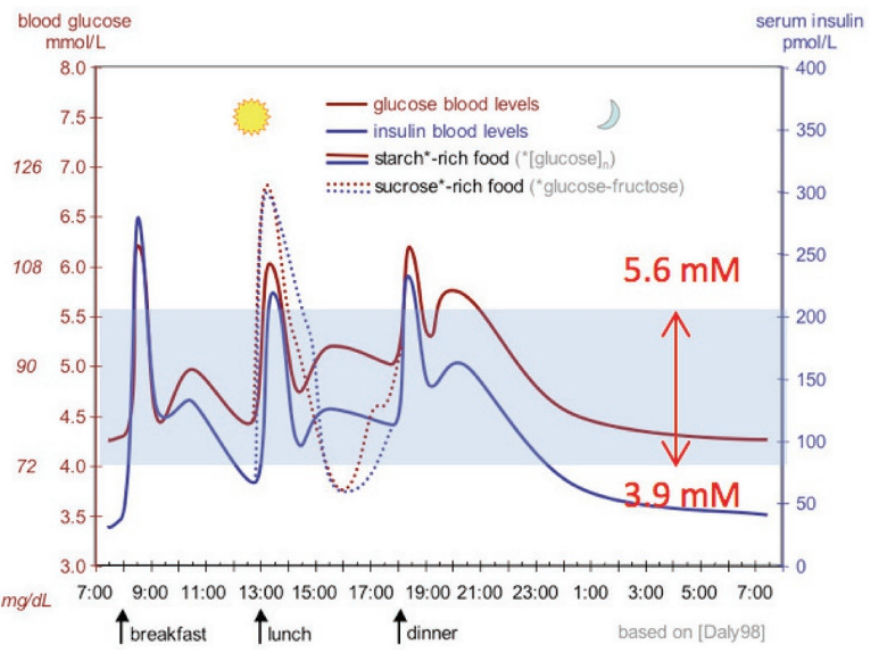

B

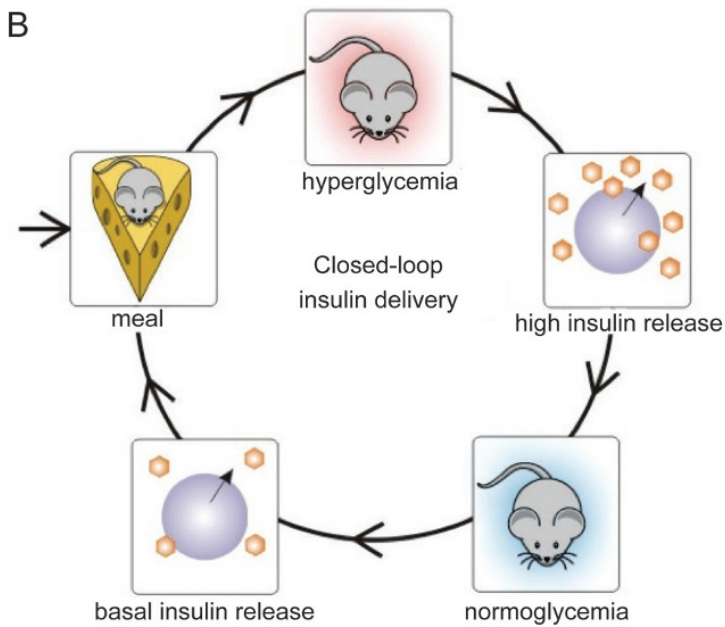

C

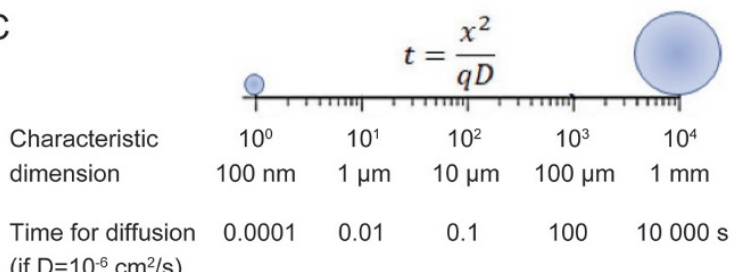

(if $\mathrm{D}=10^{-6} \mathrm{~cm}^{2} / \mathrm{s}$ )

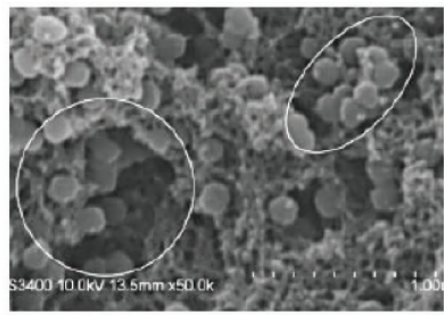

D

Mechanism of glucose-sensitive nanoparticles:

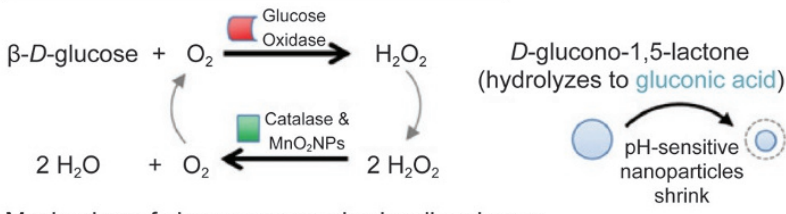

Mechanism of glucose-responsive insulin release:

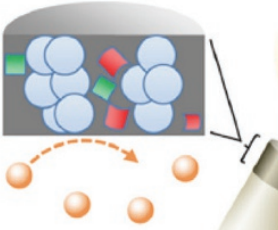

Euglycemic

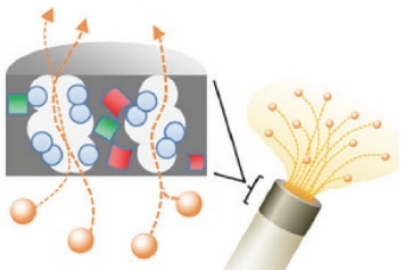

Hyperglycemic

E

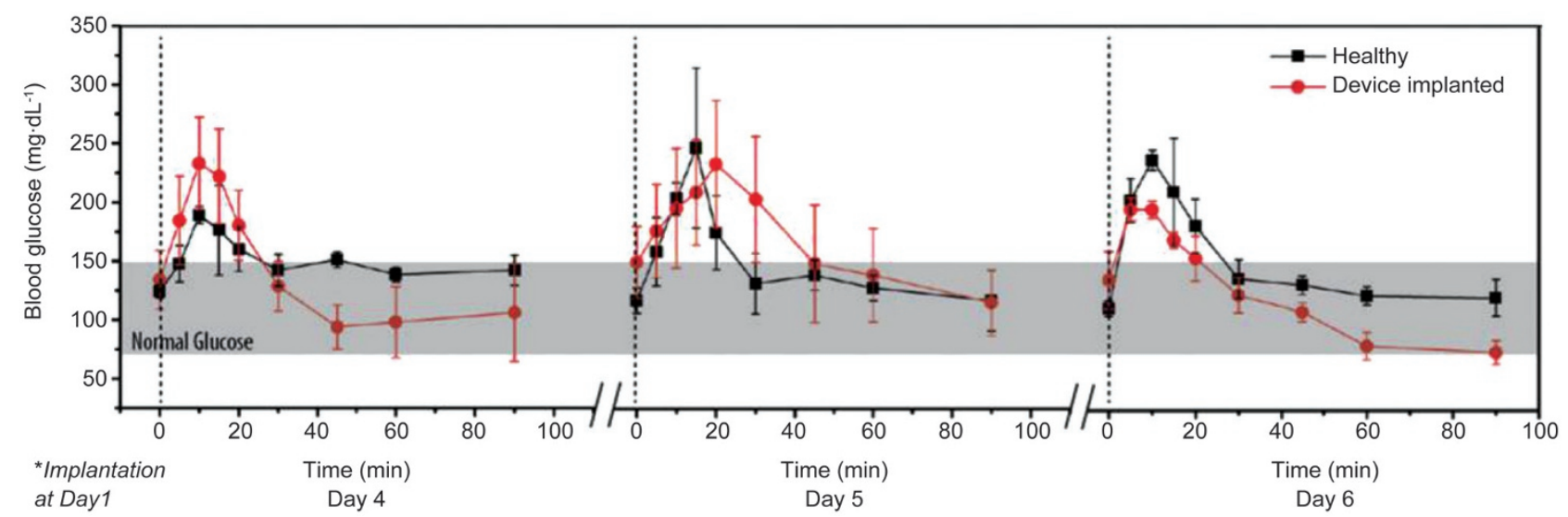

Figure 7. (A) Profile of blood glucose and insulin concentration with high-starch and high-sucrose diets. (B) Schematic illustrating the concept of closed-loop insulin delivery for the management of blood glucose levels in Type 1 diabetes patients. (C) Comparison of the time for a molecule with assumed $D=1 \times 10^{-6} \mathrm{~cm}^{2} / \mathrm{s}$ to diffuse a distance within a material with milliliter to nanometer sizes (top) and a scanning electron microscopic image of nanohydrogel particles in a composite membrane (bottom). (D) Schematic of a chemically-driven closed-loop insulin delivery device based on glucose oxidase, pH-responsive nanogel, catalase and $\mathrm{MnO}_{2} \mathrm{NPs}$. Glucose oxidase catalyzes the oxidation of environmental glucose to gluconic acid, which induces shrinkage of embedded $\mathrm{pH}$-sensitive nanogels, leading to increased membrane porosity and faster diffusive release of insulin from the device. Catalase and $\mathrm{MnO}_{2}$ nanoparticles remove by-product $\mathrm{H}_{2} \mathrm{O}_{2}$ and regenerate $\mathrm{O}_{2}$, which is required for glucose oxidation. (E) Blood glucose levels of healthy (square) and diabetic rats implanted with the closed-loop insulin delivery device (circle) over a 90 min period following a bolus injection of glucose. Error bars represent SD $(n=3)$. The implanted devices enabled blood glucose levels to return to a normal range within $\sim 30$ min after glucose injection, thus mimicking the physiological insulin response of healthy rats. The figures are reproduced from Daly et al ${ }^{[160]}$, Gordijo et al ${ }^{[172]}$, Li et al ${ }^{[169]}$ and Chu et $\mathrm{al}^{[171]}$ with permission. 
have an in-depth understanding of the pharmacological mechanisms of synergistic drug combinations, biological pathways of TME and cancer cells, and physiological characteristics of normal and disease states, in addition to the physicochemical properties of NPs (eg, size, surface charge and shapes). Initial efforts to acquire knowledge about relevant pharmacology, physiology and pathophysiology are essential for providing critical criteria for designing and evaluating nanotechnologybased drug delivery systems with desirable functionalities for the treatment of various diseases.

The importance of integrating these biological factors into the design of nanomedicine is illustrated by our firsthand preclinical examples presented herein and demonstrated by several nanomedicine products successfully developed for clinical use. The first successful example of nanomedicine translation is the design of Stealth Doxil ${ }^{\circledR}$ (Pegylated liposomal DOX) with surface PEGylation to minimize blood protein adsorption and liver uptake ${ }^{[27,180]}$. Both preclinical and clinical studies of Pegylated liposomal DOX revealed similar pharmacokinetic and toxicity profiles, including extended blood circulation of DOX and selective tumor uptake via the leaky microvasculature and reduced DOX-associated cardiotoxicity among various species and tumor types ${ }^{[27,180]}$. The biomimetic design of Abraxane ${ }^{\circledast}$ (albumin-bound paclitaxel) is another successful example that utilizes the natural binding of a hydrophobic drug to the serum protein albumin to deliver water-insoluble paclitaxel to the tumor ${ }^{[181]}$. This formulation improves the pharmacokinetics of the drug compared to the castor oil-based paclitaxel (Cremophor ${ }^{\oplus}$ EL) by two delivery mechanisms glycoprotein 60 receptor-mediated endothelial cell transcytosis and the EPR effect ${ }^{[181]}$. A recently approved liposomal formulation $\left(\mathrm{Vyxeos}^{\mathrm{TM}}\right)$ for treating acute myeloid leukemia $(\mathrm{AML})^{[182]}$ is a perfect example of the rational design of synergistic drug combination thorough pharmacological evaluation and preclinical studies followed by successful translation to human patients. The daunorubicin-cytarabine molar ratio fixed at 5:1 in the formulation was identified in vitro against leukemia cells, and the capability of the liposomes to deliver the synergistic drug ratio and provide enhanced efficacy and reduced toxicity was demonstrated in rodent tumor mod$\mathrm{els}^{[182]}$. These benefits were then translated successfully to human patients.

These aforementioned examples of bench-to-bed translation suggest that integration of nanotechnology with biology can boost the success rate of nanomedicine development. Nevertheless, extrapolation of animal data to human application is challenging. Most laboratory animals (eg, rodents, canines, pigs) have different anatomical sizes than humans, which could directly influence physiological parameters (eg, the amount of enzymes and blood flow) of their internal organs. For example, a drug administered to laboratory mice is more rapidly cleared due to the relatively higher amount of hepatic enzymes and faster blood flow than those in human being ${ }^{[183]}$. In addition, biochemical parameters such as protein binding and enzyme activity can be distinctive among species. Although the amino acid sequences of many proteins are conserved evolutionarily, small changes in the primary amino acid residues could result in profound differences in the substrate specificity of metabolizing enzymes ( $\mathrm{eg}$, albumin and cytochrome P450). This can be particularly critical in the design of drug combination nanomedicine that relies on metabolic activities for synergistic interactions ${ }^{[183]}$. Thus, it is difficult to predict all the parameters in drug metabolism, pharmacokinetics and toxicity from in vitro and preclinical experiments ${ }^{[183]}$. Currently, in addition to established physiologically relevant mathematical models, organ-on-a-chip systems that recapitulate the complex organ functions at the microscale level provide an alternative preclinical-to-clinical model to robustly evaluate drug delivery systems for reduced discrepancies between their performance in preclinical studies and clinical trials ${ }^{[184]}$.

Meanwhile, continuous investigations on intricate interactions between nanomaterials and biological systems will uncover underlying mechanisms of "black boxes" after the bio-distribution of NPs administered to the body, leading to new strategies for manipulating physiological conditions to maximize the impact of nanotherapeutics on disease treatments ${ }^{[185-188]}$. Moreover, understanding molecular interactions among NP components (ie, nanomaterials, loaded drugs) within the nanostructure can shed light on valuable mechanisms leading to the rational design of drug delivery systems with desirable physicochemical properties for precisely controlled drug loading and release $\mathrm{e}^{[51,173,189-191]}$. Fine-tuned nanocarriers and nanoconstructs will complement desired pharmacological aspects of the drug (eg, site of the drug action, ratiometric delivery) for optimal in vivo performance. We expect that the integration of nanotechnology with pharmacology and physiology will expedite the successful development and application of clinical nanotherapeutics, which in turn will make the clinical goal - improved patient survival and quality of life - become a reality in the near future.

\section{Acknowledgements}

This work is supported in part by the Canadian Breast Cancer Foundation (CBCF) - Ontario region, the Canadian Institutes of Health Research (CIHR), the National Science and Engineering Research Council (NSERC) of Canada, the Juvenile Diabetes Research Foundation (JDRF)-Lily, and the University of Toronto Connaught Innovation Award to Xiao Yu WU. University of Toronto open scholarships to Tian ZHANG, Brian LU, Mohammad A AMINI, and HoYin LIP and a University of Toronto Connaught International Scholarship for Doctoral Students to Taksim AHMED are also acknowledged.

\section{References}

1 Pelaz B, Alexiou C, Alvarez-Puebla RA, Alves F, Andrews AM, Ashraf S, et al. Diverse applications of nanomedicine. ACS Nano 2017; 11 : 2313-81.

2 Farokhzad OC, Langer R. Impact of nanotechnology on drug delivery. ACS Nano 2009; 3: 16-20.

3 Zhang RX, Ahmed T, Li LY, Li J, Abbasi AZ, Wu XY. Design of nanocarriers for nanoscale drug delivery to enhance cancer 
treatment using hybrid polymer and lipid building blocks. Nanoscale 2017; 9: 1334-55.

4 Wu XY. Strategies for optimizing polymer-lipid hybrid nanoparticlemediated drug delivery. Expert Opin Drug Deliv 2016; 13: 609-12.

5 Shi J, Kantoff PW, Wooster R, Farokhzad OC. Cancer nanomedicine: Progress, challenges and opportunities. Nat Rev Cancer 2017; 17: 20-37.

6 Zhang RX, Wong HL, Xue HY, Eoh JY, Wu XY. Nanomedicine of synergistic drug combinations for cancer therapy - strategies and perspectives. J Control Release 2016; 240: 489-503.

7 Wang $\mathrm{H}$, Jiang $\mathrm{Y}$, Peng $\mathrm{H}$, Chen $\mathrm{Y}$, Zhu P, Huang $\mathrm{Y}$. Recent progress in microrna delivery for cancer therapy by non-viral synthetic vectors. Adv Drug Deliv Rev 2015; 81: 142-60.

8 Mo R, Jiang T, Di J, Tai W, Gu Z. Emerging micro- and nanotechnology based synthetic approaches for insulin delivery. Chem Soc Rev 2014; 43: 3595-629.

9 Cash KJ, Clark HA. Nanosensors and nanomaterials for monitoring glucose in diabetes. Trends Mol Med 2010; 16: 584-93.

10 Gabathuler R. Approaches to transport therapeutic drugs across the blood-brain barrier to treat brain diseases. Neurobiol Dis 2010; 37 : 48-57.

11 Srikanth M, Kessler JA. Nanotechnology - novel therapeutics for CNS disorders. Nat Rev Neurol 2012; 8: 307-18.

12 Wilhelm S, Tavares AJ, Dai Q, Ohta S, Audet J, Dvorak HF, et al. Analysis of nanoparticle delivery to tumours. Nat Rev Mater 2016; 1 : 1-12.

13 Hare Jl, Lammers T, Ashford MB, Puri S, Storm G, Barry ST. Challenges and strategies in anti-cancer nanomedicine development: An industry perspective. Adv Drug Deliv Rev 2017; 108: 25-38.

14 Satalkar P, Elger BS, Hunziker P, Shaw D. Challenges of clinical translation in nanomedicine: A qualitative study. Nanomedicine 2016; 12: 893-900.

15 Maeda $\mathrm{H}$. Toward a full understanding of the epr effect in primary and metastatic tumors as well as issues related to its heterogeneity. Adv Drug Deliv Rev 2015; 91: 3-6.

16 Sun XX, Yu Q. Intra-tumor heterogeneity of cancer cells and its implications for cancer treatment. Acta Pharmacol Sin 2015; 36: 1219-27.

17 Blanco E, Shen H, Ferrari M. Principles of nanoparticle design for overcoming biological barriers to drug delivery. Nat Biotechnol 2015; 33: 941-51.

18 Stylianopoulos T, Jain RK. Design considerations for nanotherapeutics in oncology. Nanomedicine 2015; 11: 1893-907.

19 Maeda H, Wu J, Sawa T, Matsumura Y, Hori K. Tumor vascular permeability and the EPR effect in macromolecular therapeutics: A review. J Control Release 2000; 65: 271-84.

20 Matsumura Y, Maeda H. A new concept for macromolecular therapeutics in cancer chemotherapy: Mechanism of tumoritropic accumulation of proteins and the antitumor agent smancs. Cancer Res 1986; 46: $6387-$ 92.

21 Shuhendler AJ, Prasad P, Leung M, Rauth AM, Dacosta RS, Wu XY. A novel solid lipid nanoparticle formulation for active targeting to tumor alpha(v) beta(3) integrin receptors reveals cyclic rgd as a doubleedged sword. Adv Healthc Mater 2012; 1: 600-8.

22 Shuhendler AJ, Prasad P, Chan HK, Gordijo CR, Soroushian B, Kolios $\mathrm{M}$, et al. Hybrid quantum dot-fatty ester stealth nanoparticles: Toward clinically relevant in vivo optical imaging of deep tissue. ACS Nano 2011; 5: 1958-66.

23 Ma X, Gong N, Zhong L, Sun J, Liang XJ. Future of nanotherapeutics: Targeting the cellular sub-organelles. Biomaterials 2016; 97: 10-21.

24 Meng F, Cheng R, Deng C, Zhong Z. Intracellular drug release nanosystems. Mater Today 2012; 15: 436-42.

25 Shuhendler AJ, Prasad P, Zhang RX, Amini MA, Sun M, Liu PP, et al. Synergistic nanoparticulate drug combination overcomes multidrug resistance, increases efficacy, and reduces cardiotoxicity in a nonimmunocompromised breast tumor model. Mol Pharm 2014; 11 : 2659-74.

26 Laginha KM, Verwoert S, Charrois GJ, Allen TM. Determination of doxorubicin levels in whole tumor and tumor nuclei in murine breast cancer tumors. Clin Cancer Res 2005; 11: 6944-9.

27 Gabizon A, Shmeeda H, Barenholz Y. Pharmacokinetics of pegylated liposomal doxorubicin: Review of animal and human studies. Clin Pharmacokinet 2003; 42: 419-36.

28 O'Brien ME, Wigler N, Inbar M, Rosso R, Grischke E, Santoro A, et al. Reduced cardiotoxicity and comparable efficacy in a phase III trial of pegylated liposomal doxorubicin $\mathrm{HCl}\left(\right.$ Caelyx ${ }^{\circledR} /$ Doxil $\left.^{\circledR}\right)$ versus conventional doxorubicin for first-line treatment of metastatic breast cancer. Ann Oncol 2004; 15: 440-9.

29 Danhier F, Feron O, Preat V. To exploit the tumor microenvironment: Passive and active tumor targeting of nanocarriers for anti-cancer drug delivery. J Control Release 2010; 148: 135-46.

30 Wang $\mathrm{T}$, Wang D, Liu J, Feng B, Zhou F, Zhang H, et al. Aciditytriggered ligand-presenting nanoparticles to overcome sequential drug delivery barriers to tumors. Nano Lett 2017; 17: 5429-36.

31 Holohan C, Van Schaeybroeck S, Longley DB, Johnston PG. Cancer drug resistance: An evolving paradigm. Nat Rev Cancer 2013; 13 : 714-26.

32 Wong HL, Bendayan R, Rauth AM, Li Y, Wu XY. Chemotherapy with anticancer drugs encapsulated in solid lipid nanoparticles. Adv Drug Deliv Rev 2007; 59: 491-504.

33 Trédan O, Galmarini CM, Patel K, Tannock IF. Drug resistance and the solid tumor microenvironment. J Natl Cancer Inst 2007; 99: 1441-54.

34 Saraswathy M, Gong S. Different strategies to overcome multidrug resistance in cancer. Biotechnol Adv 2013; 31: 1397-407.

35 Ozben T. Mechanisms and strategies to overcome multiple drug resistance in cancer. FEBS Lett 2006; 580: 2903-9.

36 Zhang RX, Cai P, Zhang T, Chen K, Li J, Cheng J, et al. Polymerlipid hybrid nanoparticles synchronize pharmacokinetics of co-encapsulated doxorubicin-mitomycin $\mathrm{C}$ and enable their spatiotemporal co-delivery and local bioavailability in breast tumor. Nanomedicine 2016; 12: 1279-90.

37 Prasad P, Shuhendler A, Cai P, Rauth AM, Wu XY. Doxorubicin and mitomycin c co-loaded polymer-lipid hybrid nanoparticles inhibit growth of sensitive and multidrug resistant human mammary tumor xenografts. Cancer Lett 2013; 334: 263-73.

38 Prasad P, Cheng J, Shuhendler A, Rauth AM, Wu XY. A novel nanoparticle formulation overcomes multiple types of membrane efflux pumps in human breast cancer cells. Drug Deliv Transl Res 2012; 2: 95-105.

39 Wong HL, Rauth AM, Bendayan R, Wu XY. In vivo evaluation of a new polymer-lipid hybrid nanoparticle (PLN) formulation of doxorubicin in a murine solid tumor model. Eur J Pharm Biopharm 2007; 65: 300-8.

40 Wong HL, Rauth AM, Bendayan R, Manias JL, Ramaswamy M, Liu $Z$, et al. A new polymer-lipid hybrid nanoparticle system increases cytotoxicity of doxorubicin against multidrug-resistant human breast cancer cells. Pharm Res 2006; 23: 1574-85.

41 Wong HL, Bendayan R, Rauth AM, Xue HY, Babakhanian K, Wu XY. A mechanistic study of enhanced doxorubicin uptake and retention in multidrug resistant breast cancer cells using a polymer-lipid hybrid nanoparticle system. J Pharmacol Exp Ther 2006; 317: 1372-81. 
42 Wong HL, Bendayan R, Rauth AM, Wu XY. Simultaneous delivery of doxorubicin and GG918 (Elacridar) by new polymer-lipid hybrid nanoparticles (PLN) for enhanced treatment of multidrug-resistant breast cancer. J Control Release 2006; 116: 275-84.

43 Pinto AC, Moreira JoN, Simões Sr. Combination Chemotherapy in Cancer: Principles, Evaluation and Drug Delivery Strategies. In: Özdemir Ö, editor. Current Cancer Treatment - Novel Beyond Conventional Approaches. InTech; 2011. p 693-714.

44 Carrick S, Parker S, Thornton CE, Ghersi D, Simes J, Wilcken N. Single agent versus combination chemotherapy for metastatic breast cancer. Cochrane Database Syst Rev 2009; (2): CD003372.

45 Waterhouse DN, Gelmon KA, Klasa R, Chi K, Huntsman D, Ramsay $\mathrm{E}$, et al. Development and assessment of conventional and targeted drug combinations for use in the treatment of aggressive breast cancers. Curr Cancer Drug Targets 2006; 6: 455-89.

46 Shin HC, Alani AW, Cho H, Bae Y, Kolesar JM, Kwon GS. A 3-in-1 polymeric micelle nanocontainer for poorly water-soluble drugs. Mol Pharm 2011; 8: 1257-65.

47 Shin HC, Cho H, Lai TC, Kozak KR, Kolesar JM, Kwon GS. Pharmacokinetic study of 3-in-1 poly(ethylene glycol)-blockpoly(d, I-lactic acid) micelles carrying paclitaxel, 17-allylamino-17demethoxygeldanamycin, and rapamycin. J Control Release 2012; 163: 93-9.

48 Batist G, Gelmon KA, Chi KN, Miller WH Jr, Chia SK, Mayer LD, et al. Safety, pharmacokinetics, and efficacy of cpx-1 liposome injection in patients with advanced solid tumors. Clin Cancer Res 2009; 15: 692-700.

49 Feldman EJ, Lancet JE, Kolitz JE, Ritchie EK, Roboz GJ, List AF, et al. First-in-man study of cpx-351: A liposomal carrier containing cytarabine and daunorubicin in a fixed 5:1 molar ratio for the treatment of relapsed and refractory acute myeloid leukemia. J Clin Oncol 2011; 29: 979-85.

50 Harasym TO, Tardi PG, Harasym NL, Harvie P, Johnstone SA, Mayer LD. Increased preclinical efficacy of irinotecan and floxuridine coencapsulated inside liposomes is associated with tumor delivery of synergistic drug ratios. Oncol Res 2007; 16: 361-74.

51 Mayer LD, Harasym TO, Tardi PG, Harasym NL, Shew CR, Johnstone $\mathrm{SA}$, et al. Ratiometric dosing of anticancer drug combinations: Controlling drug ratios after systemic administration regulates therapeutic activity in tumor-bearing mice. Mol Cancer Ther 2006; 5 : 1854-63.

$52 \mathrm{Cao} \mathrm{H}$, Zou L, He B, Zeng L, Huang Y, Yu H, et al. Albumin biomimetic nanocorona improves tumor targeting and penetration for synergistic therapy of metastatic breast cancer. Adv Funct Mater 2017; 27 : 1605679-93.

53 Hasenstein JR, Shin HC, Kasmerchak K, Buehler D, Kwon GS, Kozak KR. Antitumor activity of Triolimus: A novel multidrug-loaded micelle containing Paclitaxel, Rapamycin, and 17-AAG. Mol Cancer Ther 2012; 11: 2233-42.

54 US Food \& Drug Administration. Updated 2017 Aug 4; cited 2018 Jan 08. FDA approves first treatment for certain types of poorprognosis acute myeloid leukemia. Available from: https://www.fda. gov/NewsEvents/Newsroom/PressAnnouncements/ucm569883. htm

55 US National Library of Medicine. Updated 2017 Nov 21; cited 2018 Jan 08. Pharmaceuticals J. Phase III study of CPX-351 versus $7+3$ in patients 60-75 years old with untreated high risk (secondary) acute myeloid leukemia (301). Available from: https://clinicaltrials.gov/ ct2/show/NCT01696084

56 Wardman P. Electron transfer and oxidative stress as key factors in the design of drugs selectively active in hypoxia. Curr Med Chem
2001; 8: 739-61.

57 Rauth AM, Melo T, Misra V. Bioreductive therapies: An overview of drugs and their mechanisms of action. Int J Radiat Oncol Biol Phys 1998; 42: 755-62.

58 Kennedy KA, Rockwell S, Sartorelli AC. Preferential activation of mitomycin c to cytotoxic metabolites by hypoxic tumor cells. Cancer Res 1980; 40: 2356-60.

59 Burden DA, Osheroff N. Mechanism of action of eukaryotic topoisomerase II and drugs targeted to the enzyme. Biochim Biophys Acta 1998; 1400: 139-54.

60 Tewey KM, Rowe TC, Yang L, Yang L, Halligan BD, Liu LF. Adriamycininduced DNA damage mediated by mammalian DNA topoisomerase II. Science 1984; 226: 466-8.

61 Wang P, Song Y, Zhang L, He H, Zhou X. Quinone methide derivatives: Important intermediates to DNA alkylating and DNA cross-linking actions. Curr Med Chem 2005; 12: 2893-913.

62 Hortobagyi GN. Mitomycin: Its evolving role in the treatment of breast cancer. Oncology 1993; 50: 1-8.

63 Andersson M, Daugaard S, von der Maase H, Mouridsen HT. Doxorubicin versus mitomycin versus doxorubicin plus mitomycin in advanced breast cancer: A randomized study. Cancer Treat Rep 1986; 70: 1181-6.

64 Zhang RX, Zhang T, Chen K, Cheng J, Lai P, Rauth AM, et al. Sample extraction and simultaneous chromatographic quantitation of doxorubicin and mitomycin $\mathrm{C}$ following drug combination delivery in nanoparticles to tumor-bearing mice. J Vis Exp 2017; 128: e5615970.

65 Shuhendler AJ, Cheung RY, Manias J, Connor A, Rauth AM, Wu $\mathrm{XY}$. A novel doxorubicin-mitomycin $\mathrm{C}$ co-encapsulated nanoparticle formulation exhibits anti-cancer synergy in multidrug resistant human breast cancer cells. Breast Cancer Res Treat 2010; 119: 255-69.

66 Shuhendler AJ, O'Brien PJ, Rauth AM, Wu XY. On the synergistic effect of doxorubicin and mitomycin $C$ against breast cancer cells. Drug Metabol Drug Interact 2007; 22: 201-33.

67 Cheung RY, Rauth AM, Ronaldson PT, Bendayan R, Wu XY. In vitro toxicity to breast cancer cells of microsphere-delivered mitomycin $\mathrm{C}$ and its combination with doxorubicin. Eur J Pharm Biopharm 2006; 62: 321-31.

68 Cheung RY, Rauth AM, Yu Wu X. In vivo efficacy and toxicity of intratumorally delivered mitomycin $c$ and its combination with doxorubicin using microsphere formulations. Anticancer Drugs 2005; 16: 423-33.

69 Muller MR, Wright KA, Twentyman PR. Differential properties of cisplatin and tetraplatin with respect to cytotoxicity and perturbation of cellular glutathione levels. Cancer Chemother Pharmacol 1991; 28: 273-6.

70 Zhang S, Gao H, Bao G. Physical principles of nanoparticle cellular endocytosis. ACS Nano 2015; 9: 8655-71.

71 Peetla C, Bhave R, Vijayaraghavalu S, Stine A, Kooijman E, Labhasetwar V. Drug resistance in breast cancer cells: Biophysical characterization of and doxorubicin interactions with membrane lipids. Mol Pharm 2010; 7: 2334-48.

72 Peetla C, Jin S, Weimer J, Elegbede A, Labhasetwar V. Biomechanics and thermodynamics of nanoparticle interactions with plasma and endosomal membrane lipids in cellular uptake and endosomal escape. Langmuir 2014; 30: 7522-32.

73 Peetla C, Vijayaraghavalu S, Labhasetwar V. Biophysics of cell membrane lipids in cancer drug resistance: Implications for drug transport and drug delivery with nanoparticles. Adv Drug Deliv Rev 2013; 65: 1686-98.

74 Liang XJ, Meng H, Wang Y, He H, Meng J, Lu J, et al. Metallofullerene 
nanoparticles circumvent tumor resistance to cisplatin by reactivating endocytosis. Proc Natl Acad Sci U S A 2010; 107: 7449-54.

75 Baek AE, Yu YA, He S, Wardell SE, Chang CY, Kwon S, et al. The cholesterol metabolite 27 hydroxycholesterol facilitates breast cancer metastasis through its actions on immune cells. Nat Commun 2017; 8: 864-78.

76 McDonnell DP, Park S, Goulet MT, Jasper J, Wardell SE, Chang CY, et al. Obesity, cholesterol metabolism, and breast cancer pathogenesis. Cancer Res 2014; 74: 4976-82.

77 Kaiser J. Cholesterol forges link between obesity and breast cancer. Science 2013; 342: 1028.

78 Zhang RX, Li LY, Li J, Xu Z, Abbasi AZ, Lin L, et al. Coordinating biointeraction and bioreaction of a nanocarrier material and an anticancer drug to overcome membrane rigidity and target mitochondria in multidrug-resistant cancer cells. Adv Funct Mater 2017: 1700804-16.

79 Stillwell W, Wassall SR. Docosahexaenoic acid: Membrane properties of a unique fatty acid. Chem Phys Lipids 2003; 126: 1-27.

80 Merendino N, Costantini L, Manzi L, Molinari R, D'Eliseo D, Velotti F. Dietary omega-3 polyunsaturated fatty acid DHA: A potential adjuvant in the treatment of cancer. Biomed Res Int 2013; 2013: 310186-97.

81 Steeg PS. Targeting metastasis. Nat Rev Cancer 2016; 16: 201-18.

82 Guan X. Cancer metastases: Challenges and opportunities. Acta Pharm Sin B 2015; 5: 402-18.

83 Cancer Research UK. Updated 2016 Apr 30; cited 2018 Jan 08. Radiotherapy side effects. Available from: http://www. cancerresearchuk.org/about-cancer/cancer-in-general/treatment/ radiotherapy/side-effects

84 Dean M, Fojo T, Bates S. Tumour stem cells and drug resistance. Nat Rev Cancer 2005; 5: 275-84.

85 Bae YH, Park K. Targeted drug delivery to tumors: Myths, reality and possibility. J Control Release 2011; 153: 198-205.

86 Liang C, Xu L, Song G, Liu Z. Emerging nanomedicine approaches fighting tumor metastasis: Animal models, metastasis-targeted drug delivery, phototherapy, and immunotherapy. Chem Soc Rev 2016; 45: 6250-69.

87 Schroeder A, Heller DA, Winslow MM, Dahlman JE, Pratt GW, Langer R, Jacks $\mathrm{T}$, et al. Treating metastatic cancer with nanotechnology. Nat Rev Cancer 2012; 12: 39-50.

88 Ganapathy V, Moghe PV, Roth CM. Targeting tumor metastases: Drug delivery mechanisms and technologies. J Control Release 2015; 219: 215-23.

89 Seo JB, Im JG, Goo JM, Chung MJ, Kim MY. Atypical pulmonary metastases: Spectrum of radiologic findings. Radiographics 2001; 21: 403-17.

90 Wang $\mathrm{H}$, Zhang $\mathrm{C}$, Zhang J, Kong L, Zhu H, Yu J. The prognosis analysis of different metastasis pattern in patients with different breast cancer subtypes: A seer based study. Oncotarget 2017; 8: 26368-79.

91 Pastorino U, Buyse M, Friedel G, Ginsberg RJ, Girard P, Goldstraw P, et al. Long-term results of lung metastasectomy: Prognostic analyses based on 5206 cases. J Thorac Cardiovasc Surg 1997; 113: 37-49.

92 Chikarmane SA, Tirumani SH, Howard SA, Jagannathan JP, DiPiro PJ. Metastatic patterns of breast cancer subtypes: What radiologists should know in the era of personalized cancer medicine. Clin Radiol 2015; 70: 1-10.

93 Desgrosellier JS, Cheresh DA. Integrins in cancer: Biological implications and therapeutic opportunities. Nat Rev Cancer 2010; 10: 9-22.

94 Sheldrake HM, Patterson LH. Function and antagonism of beta3 integrins in the development of cancer therapy. Curr Cancer Drug
Targets 2009; 9: 519-40.

95 Danhier F, Le Breton A, Preat V. Rgd-based strategies to target alpha(v) beta(3) integrin in cancer therapy and diagnosis. Mol Pharm 2012; 9: 2961-73.

96 Shan D, Li J, Cai P, Prasad P, Liu F, Rauth AM, et al. RGD-conjugated solid lipid nanoparticles inhibit adhesion and invasion of alpha(v) beta(3) integrin-overexpressing breast cancer cells. Drug Deliv Transl Res 2015; 5: 15-26.

97 Owens DE 3rd, Peppas NA. Opsonization, biodistribution, and pharmacokinetics of polymeric nanoparticles. Int J Pharm 2006; 307: 93-102.

98 Zhang T, Prasad P, Cai P, He C, Shan D, Rauth AM, et al. Dualtargeted hybrid nanoparticles of synergistic drugs for treating lung metastases of triple negative breast cancer in mice. Acta Pharmacol Sin 2017; 38: 835-47.

99 Conforti G, Dominguez-Jimenez C, Zanetti A, Gimbrone MA Jr, Cremona O, Marchisio PC, et al. Human endothelial cells express integrin receptors on the luminal aspect of their membrane. Blood 1992; 80: 437-46.

100 Virtanen I, Korhonen M, Kariniemi AL, Gould VE, Laitinen L, Ylänne J. Integrins in human cells and tumors. Cell Differ Dev 1990; 32: 215-27.

101 Prieto J, Eklund A, Patarroyo M. Regulated expression of integrins and other adhesion molecules during differentiation of monocytes into macrophages. Cell Immunol 1994; 156: 191-211.

102 Quigley MR, Fukui O, Chew B, Bhatia S, Karlovits S. The shifting landscape of metastatic breast cancer to the CNS. Neurosurg Rev 2013; 36: 377-82.

103 Witzel I, Oliveira-Ferrer L, Pantel K, Müller V, Wikman H. Breast cancer brain metastases: Biology and new clinical perspectives. Breast Cancer Res 2016; 18: 8-17.

104 Reynolds JL, Mahato RI. Nanomedicines for the treatment of CNS diseases. J Neuroimmune Pharmacol 2017; 12: 1-5.

105 Wong HL, Wu XY, Bendayan R. Nanotechnological advances for the delivery of CNS therapeutics. Adv Drug Deliv Rev 2012; 64: 686700.

106 Saraiva C, Praca C, Ferreira R, Santos T, Ferreira L, Bernardino L. Nanoparticle-mediated brain drug delivery: Overcoming blood-brain barrier to treat neurodegenerative diseases. J Control Release 2016; 235: 34-47.

107 Banks WA. From blood-brain barrier to blood-brain interface: New opportunities for CNS drug delivery. Nat Rev Drug Discov 2016; 15: 275-92.

108 Pardridge WM. Drug transport across the blood-brain barrier. J Cereb Blood Flow Metab 2012; 32: 1959-72.

109 Pardridge WM, Boado RJ. Reengineering biopharmaceuticals for targeted delivery across the blood-brain barrier. Methods Enzymol 2012; 503: 269-92.

$110 \mathrm{Gao} \mathrm{H}$. Progress and perspectives on targeting nanoparticles for brain drug delivery. Acta Pharm Sin B 2016; 6: 268-86.

111 Dufes C, Al Robaian M, Somani S. Transferrin and the transferrin receptor for the targeted delivery of therapeutic agents to the brain and cancer cells. Ther Deliv 2013; 4: 629-40.

112 Ruan S, Yuan M, Zhang L, Hu G, Chen J, Cun X, et al. Tumor microenvironment sensitive doxorubicin delivery and release to glioma using angiopep-2 decorated gold nanoparticles. Biomaterials 2015; 37: 425-35.

113 Demeule M, Poirier J, Jodoin J, Bertrand Y, Desrosiers RR, Dagenais C, et al. High transcytosis of melanotransferrin (p97) across the bloodbrain barrier. J Neurochem 2002; 83: 924-33.

114 Demeule M, Regina A, Che C, Poirier J, Nguyen T, Gabathuler R, et al. 
Identification and design of peptides as a new drug delivery system for the brain. J Pharmacol Exp Ther 2008; 324: 1064-72.

115 Michaelis K, Hoffmann MM, Dreis S, Herbert E, Alyautdin RN, Michaelis $\mathrm{M}$, et al. Covalent linkage of apolipoprotein e to albumin nanoparticles strongly enhances drug transport into the brain. J Pharmacol Exp Ther 2006; 317: 1246-53.

116 Bockenhoff A, Cramer S, Wolte P, Knieling S, Wohlenberg C, Gieselmann $\mathrm{V}$, et al. Comparison of five peptide vectors for improved brain delivery of the lysosomal enzyme arylsulfatase A. J Neurosci 2014; 34: 3122-9.

117 Pardridge WM. Blood-brain barrier drug delivery of igg fusion proteins with a transferrin receptor monoclonal antibody. Expert Opin Drug Deliv 2015; 12: 207-22.

118 Harding FA, Stickler MM, Razo J, DuBridge RB. The immunogenicity of humanized and fully human antibodies: Residual immunogenicity resides in the cdr regions. MAbs 2010; 2: 256-65.

119 Wong HL, Wu XY, Bendayan R. Nanotechnological advances for the delivery of cns therapeutics. Adv Drug Deliv Rev 2012; 64: 686700.

120 Zhou Y, He C, Chen K, Ni J, Cai Y, Guo X, et al. A new method for evaluating actual drug release kinetics of nanoparticles inside dialysis devices via numerical deconvolution. J Control Release 2016; 243: 11-20.

121 Lin T, Zhao P, Jiang Y, Tang Y, Jin H, Pan Z, et al. Blood-brain-barrierpenetrating albumin nanoparticles for biomimetic drug delivery via albumin-binding protein pathways for antiglioma therapy. ACS Nano 2016; 10: 9999-10012.

122 Shalviri A, Raval G, Prasad P, Chan C, Liu Q, Heerklotz H, et al. $\mathrm{PH}-d e p e n d e n t$ doxorubicin release from terpolymer of starch, polymethacrylic acid and polysorbate 80 nanoparticles for overcoming multi-drug resistance in human breast cancer cells. Eur J Pharm Biopharm 2012; 82: 587-97.

123 Shalviri A, Chan HK, Raval G, Abdekhodaie MJ, Liu Q, Heerklotz $\mathrm{H}$, et al. Design of ph-responsive nanoparticles of terpolymer of poly(methacrylic acid), polysorbate 80 and starch for delivery of doxorubicin. Colloids Surf B Biointerfaces 2013; 101: 405-13.

124 Shalviri A, Foltz WD, Cai P, Rauth AM, Wu XY. Multifunctional terpolymeric mri contrast agent with superior signal enhancement in blood and tumor. J Control Release 2013; 167: 11-20.

125 Kreuter J. Mechanism of polymeric nanoparticle-based drug transport across the blood-brain barrier (BBB). J Microencapsul 2013; 30: 49-54.

126 Kreuter J, Ramge P, Petrov V, Hamm S, Gelperina SE, Engelhardt B, et al. Direct evidence that polysorbate-80-coated poly(butylcyanoacrylate) nanoparticles deliver drugs to the CNS via specific mechanisms requiring prior binding of drug to the nanoparticles. Pharm Res 2003; 20: 409-16.

127 Wagner S, Zensi A, Wien SL, Tschickardt SE, Maier W, Vogel T, et al. Uptake mechanism of ApoE-modified nanoparticles on brain capillary endothelial cells as a blood-brain barrier model. PLoS One 2012; 7: e32568-75.

128 Li J, Cai P, Shalviri A, Henderson JT, He C, Foltz WD, et al. A multifunctional polymeric nanotheranostic system delivers doxorubicin and imaging agents across the blood-brain barrier targeting brain metastases of breast cancer. ACS Nano 2014; 8: 9925-40.

129 Shalviri A, Cai P, Rauth AM, Henderson JT, Wu XY. Evaluation of new bi-functional terpolymeric nanoparticles for simultaneous in vivo optical imaging and chemotherapy of breast cancer. Drug Deliv TransI Res 2012; 2: 437-53.

130 He C, Cai P, Li J, Zhang T, Lin L, Abbasi AZ, et al. Blood-brain barrier- penetrating amphiphilic polymer nanoparticles deliver docetaxel for the treatment of brain metastases of triple negative breast cancer. J Control Release 2017; 246: 98-109.

131 He C, Li J, Cai P, Ahmed T, Henderson JT, Foltz WD, et al. Two-step targeted hybrid nanoconstructs increase brain penetraion and efficacy of the therapeutic anitbody trastuzumab against brain metastasis of Her2 positive breast cancer. Adv Funct Mater 2018; 28: 1705668.

132 Denko NC. Hypoxia, HIF1 and glucose metabolism in the solid tumour. Nat Rev Cancer 2008; 8: 705-13.

133 Hockel M, Vaupel P. Tumor hypoxia: Definitions and current clinical, biologic, and molecular aspects. J Natl Cancer Inst 2001; 93: 26676.

134 Yang S, Gao H. Nanoparticles for modulating tumor microenvironment to improve drug delivery and tumor therapy. Pharmacol Res 2017; 126: 97-108.

135 De Palma M, Biziato D, Petrova TV. Microenvironmental regulation of tumour angiogenesis. Nat Rev Cancer 2017; 17: 457-75.

136 Barker HE, Paget JT, Khan AA, Harrington KJ. The tumour microenvironment after radiotherapy: Mechanisms of resistance and recurrence. Nat Rev Cancer 2015; 15: 409-25.

137 Rockwell S, Dobrucki IT, Kim EY, Marrison ST, Vu VT. Hypoxia and radiation therapy: Past history, ongoing research, and future promise. Curr Mol Med 2009; 9: 442-58.

138 Hall EJ, Giaccia AJ, editors. Radiobiology for the radiologist. Lippincott Williams \& Wilkins; 2006.

139 Semenza GL. Intratumoral hypoxia, radiation resistance, and HIF-1. Cancer Cell 2004; 5: 405-6.

140 Powis G, Kirkpatrick L. Hypoxia inducible factor- $1 \alpha$ as a cancer drug target. Mol Cancer Ther 2004; 3: 647-54.

141 Cairns RA, Harris IS, Mak TW. Regulation of cancer cell metabolism. Nat Rev Cancer 2011; 11: 85-95.

142 Vaupel P. The role of hypoxia-induced factors in tumor progression. Oncologist 2004; 9: 10-7.

143 Finger EC, Giaccia AJ. Hypoxia, inflammation, and the tumor microenvironment in metastatic disease. Cancer Metastasis Rev 2010; 29: 285-93.

144 Semenza GL. Defining the role of hypoxia-inducible factor 1 in cancer biology and therapeutics. Oncogene 2010; 29: 625-34.

145 Hendriksen EM, Span PN, Schuuring J, Peters JP, Sweep FC, van der Kogel AJ, et al. Angiogenesis, hypoxia and VEGF expression during tumour growth in a human xenograft tumour model. Microvasc Res 2009; 77: 96-103.

146 Stoeltzing O, McCarty MF, Wey JS, Fan F, Liu W, Belcheva A, et al. Role of hypoxia-inducible factor 1alpha in gastric cancer cell growth, angiogenesis, and vessel maturation. J Natl Cancer Inst 2004; 96 : 946-56.

147 Benej M, Pastorekova S, Pastorek J. Carbonic anhydrase ix: Regulation and role in cancer. Subcell Biochem 2014; 75: 199-219.

148 Semenza GL. Oxygen sensing, homeostasis, and disease. N Engl J Med 2011; 365: 537-47.

149 Solaini G, Baracca A, Lenaz G, Sgarbi G. Hypoxia and mitochondrial oxidative metabolism. Biochim Biophys Acta 2010; 1797: 1171-7.

150 Gatenby RA, Gillies RJ. Why do cancers have high aerobic glycolysis? Nat Rev Cancer 2004; 4: 891.

151 Chiche J, Brahimi-Horn MC, Pouysségur J. Tumour hypoxia induces a metabolic shift causing acidosis: A common feature in cancer. J Cell Mol Med 2010; 14: 771-94.

152 Gordijo CR, Abbasi AZ, Amini MA, Lip HY, Maeda A, Cai P, et al. Design of hybrid $\mathrm{MnO}_{2}$-polymer-lipid nanoparticles with tunable oxygen generation rates and tumor accumulation for cancer 
treatment. Adv Funct Mater 2015; 25: 1858-72.

153 Gordijo CR, Wu XY. A new life to an old material. Materialstoday. 2015 Mar 5 (cited 2018 Jan 08); Available from: https://www. materialstoday.com/biomaterials/comment/a-new-life-to-an-oldmaterial/

154 Prasad P, Gordijo CR, Abbasi AZ, Maeda A, Ip A, Rauth AM, et al. Multifunctional albumin- $\mathrm{MnO}_{2}$ nanoparticles modulate solid tumor microenvironment by attenuating hypoxia, acidosis, vascular endothelial growth factor and enhance radiation response. ACS Nano 2014; 8: 3202-12.

155 Abbasi AZ, Gordijo CR, Amini MA, Maeda A, Rauth AM, DaCosta RS, et al. Hybrid manganese dioxide nanoparticles potentiate radiation therapy by modulating tumor hypoxia. Cancer Res 2016; 76: 664356.

156 Amini MA, Abbasi AZ, Cai P, Lip H, Gordijo C, Zhang L, et al. Tumor microenvironment-modulating nanoparticles boost chemotherapy efficacy and anti-tumor immunity. Annual meeting of American Association of Pharmaceutical Sciences; 2017 Nov 12-15; San Diego, CA, USA.; Poster ID:M4058.

157 World Health Organization. 10 facts on diabetes. Updated 2016 Apr; cited 2018 Jan 08. Available from: http://www.who.int/features/ factfiles/diabetes/en/

158 Atkinson MA. The pathogenesis and natural history of type 1 diabetes. Cold Spring Harb Perspect Med 2012; 2: a007641-59.

159 Bluestone JA, Herold K, Eisenbarth G. Genetics, pathogenesis and clinical interventions in type[thinsp]1 diabetes. Nature 2010; 464: 1293-300.

160 Daly ME, Vale C, Walker M, Littlefield A, Alberti KG, Mathers JC. Acute effects on insulin sensitivity and diurnal metabolic profiles of a highsucrose compared with a high-starch diet. Am J Clin Nutr 1998; 67: 1186-96.

161 Diagnosis and classification of diabetes mellitus. Diabetes Care 2008; 31: S55-60.

162 DiPiro JT, Talbert RL, Yee GC, Matzke GR, Wells BG, Posey LM, editors. Pharmacotherapy: A pathophysiologic approach. $8^{\text {th }}$ edition. McGraw-Hill Education; 2011.

163 Loghmani E. Diabetes mellitus: Type 1 and type 2. In: Stang J, Story M, editors. Guide-lines for Adolescent Nutrition Services. 2005: $p$ 167-82. Available from: http://www.epi.umn.edu/let/pubs/img/ adol_ch14.pdf

164 McGibbon A, Richardson C, Hernandez C, Dornan J. Pharmacotherapy in type 1 diabetes. Can J Diabetes 2013; 37: S56-60.

165 van Belle TL, Coppieters KT, von Herrath MG. Type 1 diabetes: Etiology, immunology, and therapeutic strategies. Physiol Rev 2011; 91: 79-118.

166 Pozzilli P, Battelino T, Danne T, Hovorka R, Jarosz-Chobot P, Renard E. Continuous subcutaneous insulin infusion in diabetes: Patient populations, safety, efficacy, and pharmacoeconomics. Diabetes Metab Res Rev 2016; 32: 21-39.

167 Heinemann L, Krinelke L. Insulin infusion set: The achilles heel of continuous subcutaneous insulin infusion. J Diabetes Sci Technol 2012; 6: 954-64.

168 Gordijo CR, Koulajian K, Shuhendler AJ, Bonifacio LD, Huang HY, Chiang $\mathrm{S}$, et al. Nanotechnology-enabled closed loop insulin delivery device: In vitro and in vivo evaluation of glucose-regulated insulin release for diabetes control. Adv Funct Mater 2011; 21: 73-82.

169 Li J, Chu MK, Gordijo CR, Abbasi AZ, Chen K, Adissu HA, et al. Microfabricated microporous membranes reduce the host immune response and prolong the functional lifetime of a closed-loop insulin delivery implant in a type 1 diabetic rat model. Biomaterials 2015;
47: 51-61.

170 Chu MK, Chen J, Gordijo CR, Chiang S, Ivovic A, Koulajian K, et al. In vitro and in vivo testing of glucose-responsive insulin-delivery microdevices in diabetic rats. Lab Chip 2012; 12: 2533-9.

171 Chu MK, Gordijo CR, Li J, Abbasi AZ, Giacca A, Plettenburg 0, et al. In vivo performance and biocompatibility of a subcutaneous implant for real-time glucose-responsive insulin delivery. Diabetes Technol Ther 2015; 17: 255-67.

172 Gordijo CR, Shuhendler AJ, Wu XY. Glucose-responsive bioinorganic nanohybrid membrane for self-regulated insulin release. Adv Funct Mater 2010; 20: 1404-12.

173 Li J, Chu MK, Lu B, Mirzaie S, Chen K, Gordijo CR, et al. Enhancing thermal stability of a highly concentrated insulin formulation with pluronic F-127 for long-term use in microfabricated implantable devices. Drug Deliv TransI Res 2017; 7: 529-43.

174 Zhang K, Wu XY. Modulated insulin permeation across a glucosesensitive polymeric composite membrane. J Control Release 2002; 80: $169-78$.

175 Zhang K, Huang H, Yang G, Shaw J, Yip C, Wu XY. Characterization of nanostructure of stimuli-responsive polymeric composite membranes. Biomacromolecules 2004; 5: 1248-55.

176 Zhang K, Wu XY. Temperature and ph-responsive polymeric composite membranes for controlled delivery of proteins and peptides. Biomaterials 2004; 25: 5281-91.

177 Gehrke SH. Synthesis, equilibrium swelling, kinetics, permeability and applications of environmentally responsive gels. In: Dušek $\mathrm{K}$, editor. Responsive gels: Volume transitions II. Springer Berlin Heidelberg, Berlin, Heidelberg; 1993. p 81-144.

178 Podual K, Doyle FJ 3rd, Peppas NA. Dynamic behavior of glucose oxidase-containing microparticles of poly(ethylene glycol)-grafted cationic hydrogels in an environment of changing $\mathrm{pH}$. Biomaterials 2000; 21: 1439-50.

179 Gordijo CR, Koulajian K, Shuhendler AJ, Bonifacio LD, Huang HY, Chiang $\mathrm{S}$, et al. Nanotechnology-enabled closed loop insulin delivery device: In vitro and in vivo evaluation of glucose-regulated insulin release for diabetes control. Adv Funct Mater 2011; 21: 73-82.

180 Suk JS, Xu Q, Kim N, Hanes J, Ensign LM. Pegylation as a strategy for improving nanoparticle-based drug and gene delivery. Adv Drug Deliv Rev 2016; 99: 28-51.

181 Gradishar WJ. Albumin-bound paclitaxel: A next-generation taxane. Expert Opin Pharmacother 2006; 7: 1041-53.

182 Raut LS. Novel formulation of cytarabine and daunorubicin: A new hope in AML treatment. South Asian J Cancer 2015; 4: 38-40.

$183 \mathrm{Lin} \mathrm{JH}$. Species similarities and differences in pharmacokinetics. Drug Metab Dispos 1995; 23: 1008-21.

184 Bhise NS, Ribas J, Manoharan V, Zhang YS, Polini A, Massa S, et al. Organ-on-a-chip platforms for studying drug delivery systems. J Control Release 2014; 190: 82-93.

185 Tsoi KM, MacParland SA, Ma XZ, Spetzler VN, Echeverri J, Ouyang B, et al. Mechanism of hard-nanomaterial clearance by the liver. Nat Mater 2016; 15: 1212-21.

186 Zhu S, Zhang J, Zhang L, Ma W, Man N, Liu Y, et al. Inhibition of kupffer cell autophagy abrogates nanoparticle-induced liver injury. Adv Healthc Mater 2017; 6. doi: 10.1002/adhm.201601252.

187 Sadauskas E, Wallin H, Stoltenberg M, Vogel U, Doering P, Larsen A, et al. Kupffer cells are central in the removal of nanoparticles from the organism. Part Fibre Toxicol 2007; 4: 10-7.

188 Ohara Y, Oda T, Yamada K, Hashimoto S, Akashi Y, Miyamoto R, et al. Effective delivery of chemotherapeutic nanoparticles by depleting host kupffer cells. Int J Cancer 2012; 131: 2402-10.

189 Dicko A, Frazier AA, Liboiron BD, Hinderliter A, Ellena JF, Xie X, et al. 
Intra and inter-molecular interactions dictate the aggregation state of irinotecan co-encapsulated with floxuridine inside liposomes. Pharm Res 2008; 25: 1702-13.

190 Li Y, Wong HL, Shuhendler AJ, Rauth AM, Wu XY. Molecular interactions, internal structure and drug release kinetics of rationally developed polymer-lipid hybrid nanoparticles. J Control Release
2008; 128: 60-70.

191 Li Y, Taulier N, Rauth AM, Wu XY. Screening of lipid carriers and characterization of drug-polymer-lipid interactions for the rational design of polymer-lipid hybrid nanoparticles (PLN). Pharm Res 2006; 23: $1877-87$. 